\title{
Creep Rupture of Pressurized Alloy 617 Tubes
}

\author{
J. K. Wright \\ R. N. Wright
}

September 2013

The INL is a

U.S. Department of Energy

National Laboratory

operated by

Battelle Energy Alliance

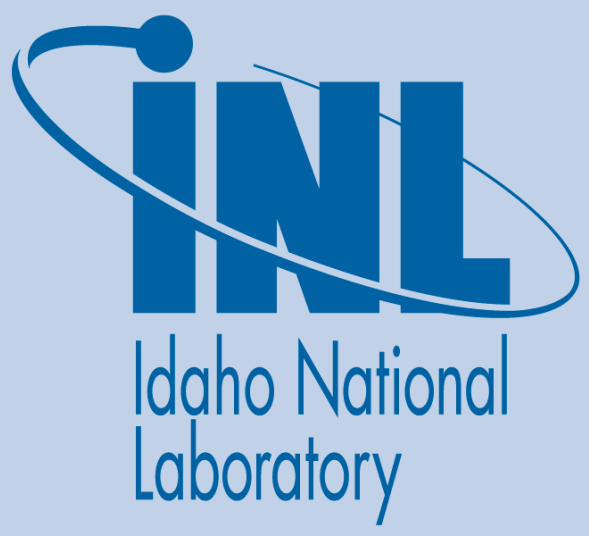




\section{DISCLAIMER}

This information was prepared as an account of work sponsored by an agency of the U.S. Government. Neither the U.S. Government nor any agency thereof, nor any of their employees, makes any warranty, expressed or implied, or assumes any legal liability or responsibility for the accuracy, completeness, or usefulness, of any information, apparatus, product, or process disclosed, or represents that its use would not infringe privately owned rights. References herein to any specific commercial product, process, or service by trade name, trade mark, manufacturer, or otherwise, does not necessarily constitute or imply its endorsement, recommendation, or favoring by the U.S. Government or any agency thereof. The views and opinions of authors expressed herein do not necessarily state or reflect those of the U.S. Government or any agency thereof. 


\title{
Creep Rupture of Pressurized Alloy 617 Tubes
}

\author{
J. K. Wright \\ R. N. Wright
}

September 2013

Idaho National Laboratory Idaho Falls, Idaho 83415

http://www.inl.gov

\author{
Prepared for the \\ U.S. Department of Energy \\ Office of Nuclear Energy \\ Under DOE Idaho Operations Office \\ Contract DE-AC07-05ID14517
}





\title{
Creep Rupture of Pressurized Alloy 617 Tubes
}

\author{
INL/EXT-13-30251
}

September 2013

Approved by:
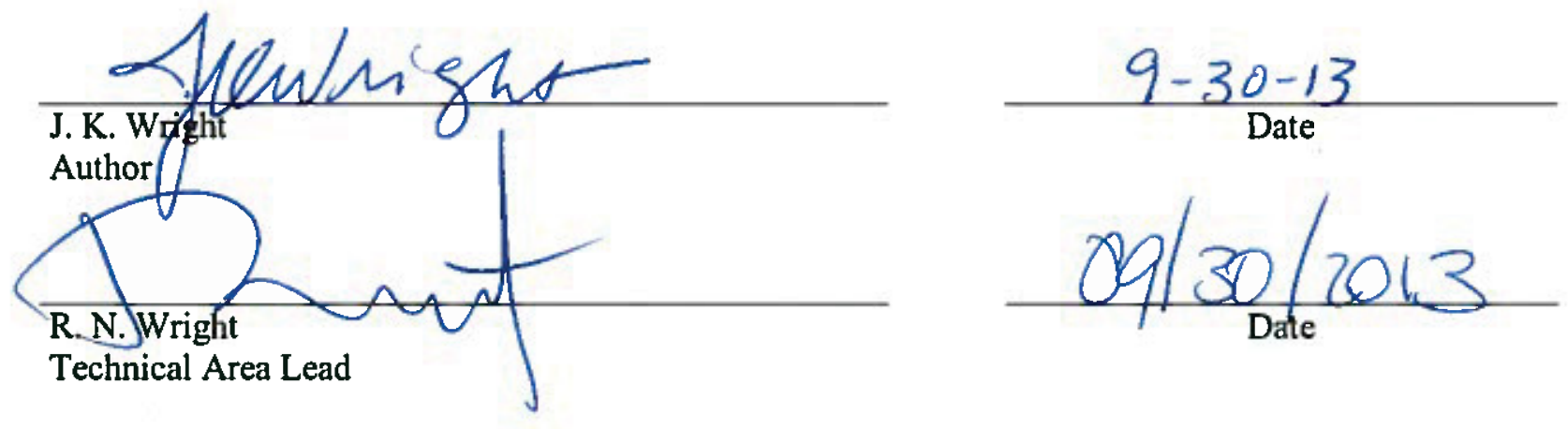


\begin{abstract}
Creep behavior of Alloy 617 under multi-axial loading has been characterized at $950^{\circ} \mathrm{C}$ using thin walled tubes with internal gas pressure. Tubes were machined from Alloy 617 plate material to ensure comparability of material properties with extensive testing carried out in the VHTR Research and Development program. Properties of this alloy under multi-axial loading are of interest for elevated temperature design in advanced nuclear heat transfer systems.
\end{abstract}

A constitutive model in the form of a Norton relationship was developed for Alloy 617 plate to allow development of a suitable creep specimen using finite element simulation. It was determined that proper description of the minimum creep rate at $750^{\circ} \mathrm{C}$ required a threshold stress formalism. The magnitude of the threshold stress was determined to be $75 \mathrm{MPa}$ for creep tests using the conditions examined. This threshold stress arises from strengthening by the $\gamma^{\prime}\left(\mathrm{Ni}_{3} \mathrm{Al}, \mathrm{Ti}\right)$ intermetallic phase; above this temperature this phase is unstable and Alloy 617 behaves as a solid solution.

Comparison of strengthening models to detailed TME analysis of dislocation- particle interaction in crept specimens indicated that strengthening arises from localized climb, or a combination of climb and Orowan bowing depending on the creep time and stress. Quantification of the strengthening from $\gamma^{\prime}$ is an important result to confirm the region over which it is acceptable to extrapolate creep rupture times on a Larson-Miller plot. This result will also help inform the activities underway in the US and Europe to develop a $\gamma^{\prime}$ strengthened version of Alloy 617 for application in ultra-supercritical fossil power plants.

Failure of the pressurized tubes initiates at low strain by cracking of the majority of grain boundaries that intersect the exterior surface. For radial strains of about $5 \%$ or less the total creep damage fraction is equivalent to uniaxial test specimens with similar tertiary creep strain. Above this value the surface nucleated cracks begin to open rapidly with increasing strain and the volume fraction of creep damage exceeds that for comparable uniaxial tests. Final failure, defined for the pressurized tubes as loss of the ability to maintain pressure, occurs by linking of damage ahead of one of the cracks that nucleate on the surface on $45^{\circ}$ angle to the tube radius.

Although the time to tube rupture was comparable to uniaxial creep rupture on the Larson-Miller diagram, cavitation was more extensive and the creep strain was considerably reduced to plate. The minimum creep rate determined from pressurized tube results appears to fit a different Monkman-Grant relationship compared to uniaxial creep data. 


\section{ACKNOWLEDGEMENTS}

Some of the experiments described in this work were carried out as part of a Senior Design Project at Boise State University. The work of the Student Team from Material Science and Engineering: Joe Croteau, Allyssa Bateman, Theodora Caldwell, and Elias Lindau and Mechanical Engineering: Justin Allen and Yudi Bhetwal is gratefully acknowledged. The assistance of W. David Swank and D. C. Haggard with developing the experimental system at INL and aiding the BSU design team is also much appreciated. Todd Morris carried out the metallographic analysis contained in this report and served as a valuable mentor for the Senior Design Team.

The information contained in this report on $\gamma^{\prime}$ strengthening of Alloy 617 at $750^{\circ} \mathrm{C}$ is taken from an analysis by T. M. Lillo, J. K. Benz and L. C. Carroll. A complete account of this work has been submitted for publication in Metallurgical and Materials Transactions. Permission to use a portion of this work is gratefully acknowledged. 


\section{ACRONYMS}

ASME - ASME International (formerly American Society of Mechanical Engineering)

BSU - Boise State University

FCC - Face Centered Cubic

FEM - Finite Element Modelling

$\gamma^{\prime}$ - gamma prime phase; $\left(\mathrm{Ni}_{3} \mathrm{Al}, \mathrm{Ti}\right)$ intermetallic

ID - Inner Diameter

INL - Idaho National Laboratory

NGNP - Next Generation Nuclear Reactor

OD - Outer Diameter

ODS - Oxide Dispersion Strengthened

psi-pounds per square inch

SMR - Small Modular Reactor

TEM - Transmission Electron Microscopy

VHTR - Very High Temperature Reactor 


\section{CONTENTS}

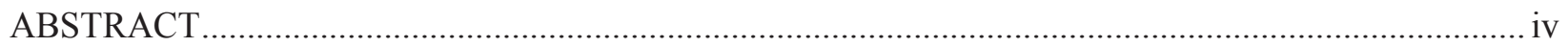

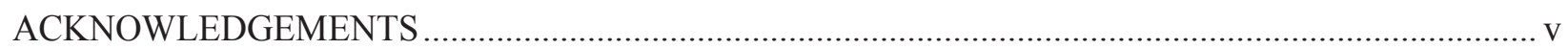

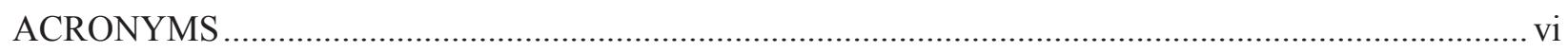

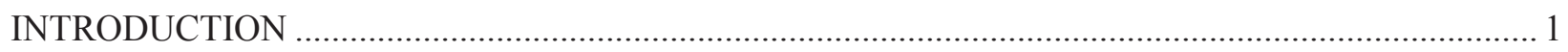

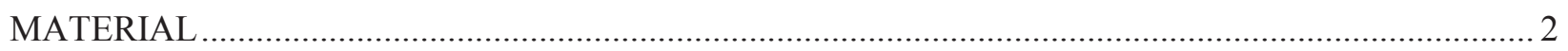

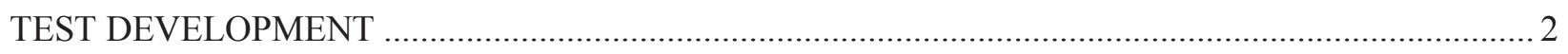

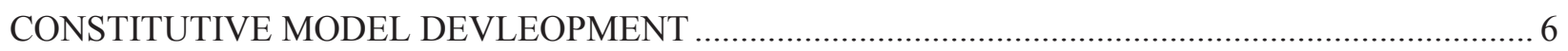

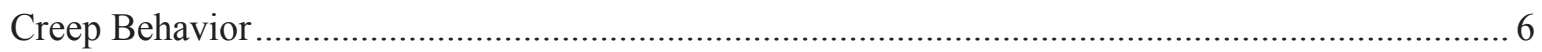

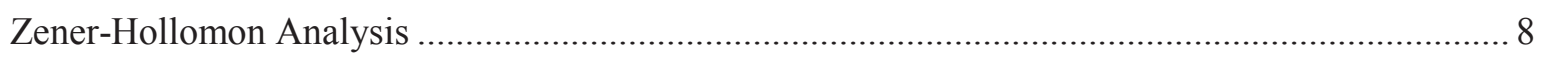

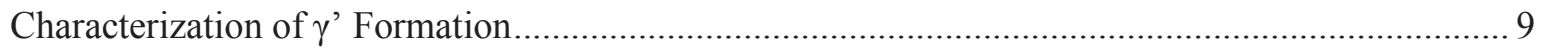

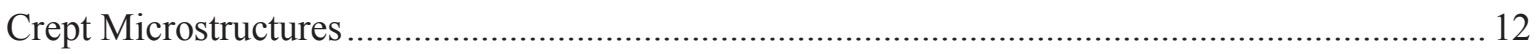

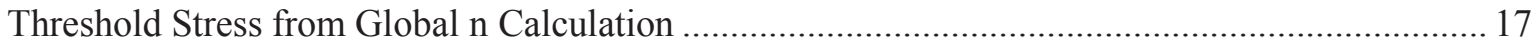

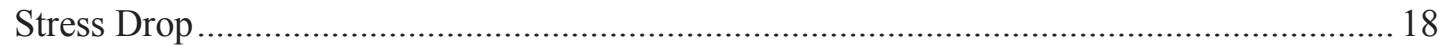

Creep Stress Exponent, Activation Energy and Threshold Stress........................................ 21

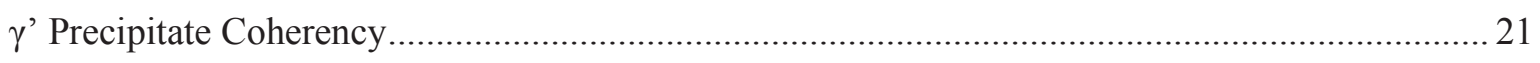

Precipitate Bypass Mechanisms Model of Threshold Stress .......................................................... 22

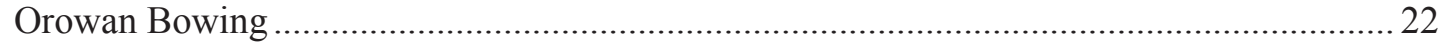

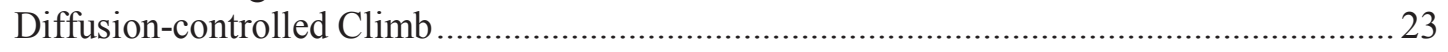

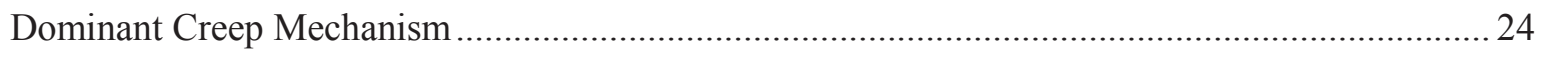

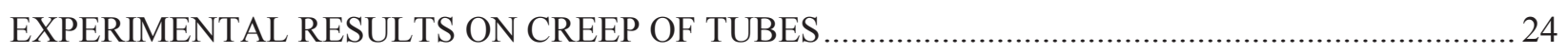

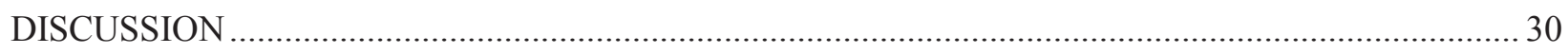

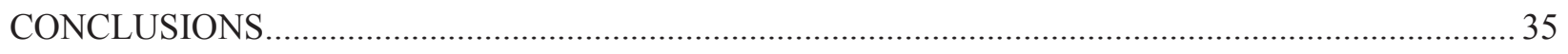

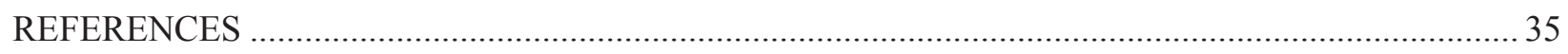

FIGURES

Figure 1. Larson-Miller plot for Alloy 617 base metal and weldments................................................. 1

Figure 2. Optical metallography of reference plate. ...........................................................................

Figure 3. Schematic comparing stress in a tensile test to stress in a pressurized tube............................. 3

Figure 4. Specimen geometry simulated using a finite element model. .................................................. 4

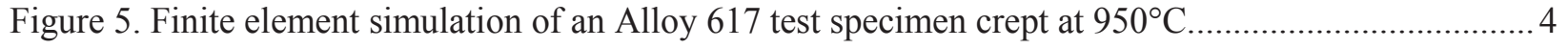

Figure 6. Piping and instrumentation diagram for gas control system............................................... 5

Figure 7. Measured temperature and gas pressure during a test segment. .............................................. 6 
Figure 8. Strain versus time of Alloy $617 \mathrm{crept}$ at $750{ }^{\circ} \mathrm{C}$ and $121 \mathrm{MPa}$ and $145 \mathrm{MPa}$ and interrupted at approximately $20 \%$ total strain. The large plot presents the 121 and 145 $\mathrm{MPa}$ data to test termination on separate time axis (121 MPa on bottom and $145 \mathrm{MPa}$ on top) to highlight the similarity in shape. The inset plots the data on a single time axis up to 1000 hours to show the primary creep region at each stress and highlight the creep rates. Arrows on the inset plot indicate the minimum creep rate determined from a mathematical minimum of a curve fit to the digital experimental data.

Figure 9. Minimum creep rate as a function of stress showing a stress exponent, $n$, ranges from 5.1 at $1000^{\circ} \mathrm{C}$ to 8.3 at $750{ }^{\circ} \mathrm{C}$. 8

Figure 10. Zener-Hollaman plot of minimum creep rates from at $750,800,900$ and $1000{ }^{\circ} \mathrm{C}$. The $750{ }^{\circ} \mathrm{C}$ data is offset to the right of the data at the other temperatures indicating threshold stress behavior......

Figure 11. Typical $\gamma^{\prime}$ precipitates imaged after static aging at $750{ }^{\circ} \mathrm{C}$ for a) $2 \mathrm{hrs}$, b) $200 \mathrm{hrs}$ and c) $5300 \mathrm{hrs}$. Superlattice reflections evident in the $<111>$ zone axis diffraction pattern representative of the ordered $\mathrm{L}_{2} \gamma^{\prime}$ precipitates $(\mathrm{d})$.

Figure 12. a) Bright field, b) weak beam, $g=<200>$ and c) weak beam, $g=<020>$, images of $\gamma^{\prime}$ precipitates in the sample aged at $750{ }^{\circ} \mathrm{C}$ for $20,000 \mathrm{hr}$. No dislocation contrast is seen in either weak beam image indicating the $\gamma^{\prime}$ particles remain coherent even after the long term aging heat treatment.

Figure 13. Bright field images of the microstructures of $750{ }^{\circ} \mathrm{C}$ creep specimens after target creep strains of 2\% (top), 5\% (middle) and 10\% (bottom) at either 121 (left column) or $145 \mathrm{MPa}$ (right column).

Figure 14. The $\gamma^{\prime}$ particle shape deviates significantly from spherical after creep strains of approximately $10 \%$ in $750{ }^{\circ} \mathrm{C}$ creep tests run at a) $121 \mathrm{MPa}$ and b) $145 \mathrm{MPa}$.

Figure 15. Weak beam TEM micrographs showing dislocation interaction with the $\gamma^{\prime}$ particles at $2 \%$ (top), 5\% (middle) and 10\% (bottom) at $121 \mathrm{MPa}$ (left) and $145 \mathrm{MPa}$ (right). White arrows identify dislocation (or impending) loop events, the black arrow indicates local dislocation climb.

Figure 16. Lagneborg-Bergman plot showing the minimum creep rates raised to the $1 / n$-power for determination of the threshold stress with $n$ of 5.6.......

Figure 17. Schematic drawing showing the characteristic strain evolution following a stress reduction during a stress drop experiment.

Figure 18. Plots of the stress drop tests at (a) $750{ }^{\circ} \mathrm{C}$ and (b) $900{ }^{\circ} \mathrm{C}$. The broken curves indicate the fit to the Henderson and McLean model and give threshold stress values of approx. 76.5 and 3.2 $\mathrm{MPa}$ for (a) and (b), respectively.

Figure 19. Zener-Holloman plot using a threshold stress of $65 \mathrm{MPa}$ on the $750{ }^{\circ} \mathrm{C}$ data. The resulting regression equation is also shown......

Figure 20. Tube diameter as a function of axial position and time of exposure ......................................25

Figure 21. Radial creep strain as a function of test time for pressurized tube experiments......................26

Figure 22. Comparison of creep curves from several pressurized tubes to a conventional uniaxial creep test under similar stress. .27

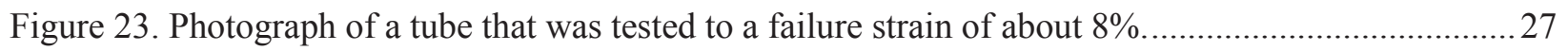

Figure 24. Macrograph showing tube fracture that resulted in gas leakage............................................28 
Figure 25. Cross-sections of the tube crept at $23 \mathrm{MPa}$ from regions that experienced (a) $6 \%$ and (b) $8 \%$ strain.

Figure 26. Etched cross-section through a tube that experienced approximately $10 \%$ strain.................... 30

Figure 27. A fracture that traverses the entire thickness of the tube wall ................................................ 30

Figure 28. Average porosity in the gage section from interrupted conventional uniaxial creep tests

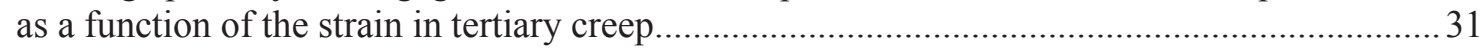

Figure 29. Average porosity in the gage section of interrupted conventional creep specimens as a function of the normalized creep stress.

Figure 30. Etched microstructure showing carbides along the grain boundaries in the area below the denuded zone near the surface that occurs as a result of oxidation.

Figure 31. Larson-Miller plot for time to rupture of uniaxial specimens and pressurized tubes.

Figure 32. Monkman-Grant plot of time to rupture as a function of minimum creep rate for uniaxial specimens and pressurized tubes.

\section{TABLES}

Table 1. Chemical Analysis of ThyssenKrupp VDM, Inc. heat number 314626.....................................2

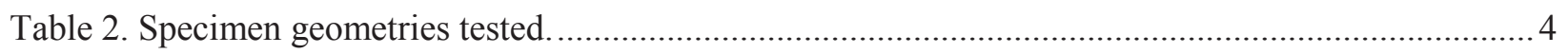

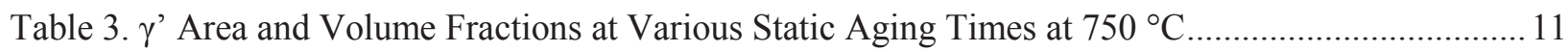

Table 4. Influence of Applied Stress on Creep Test Duration and $\gamma^{\prime}$ Precipitate Radius .......................... 13

Table 5. Applied Stress versus Critical Stresses Required for Dislocation Bypass during

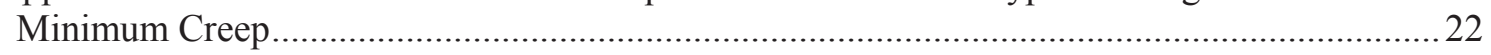

Table 6. Test pressure, dimensions and calculated stresses for pressurized tube creep specimens. ...........25 


\section{INTRODUCTION}

Alloy 617 is approved for non-nuclear construction in the ASME Boiler and Pressure Vessel Code Section I and Section VIII, but is not currently qualified for nuclear use in ASME Code Section III. A draft Code Case was developed in the 1980's to qualify the alloy for nuclear service but efforts were stopped before the approval process was completed. ${ }^{1}$ Renewed interest in high temperature nuclear reactors has resulted in a new effort to qualify Alloy 617 for use in nuclear pressure vessels.

The mechanical and physical properties of Alloy 617 were extensively characterized for the VHTR programs in the 1980's and incorporated in the draft Code Case. Recently, the properties of modern heats of the alloy that incorporate an additional processing step, electro-slag remelting, have been characterized both to confirm that the properties of contemporary material are consistent with those in the historical record and to increase the available database. An example of the extent of the available information is the Larson-Miller plot for Alloy 617 shown in Figure 1. The figure contains data from historical data, recent investigations carried out for VHTR application and data from an investigation into Alloy 617 properties for application in fossil fired power plants. ${ }^{2-4}$

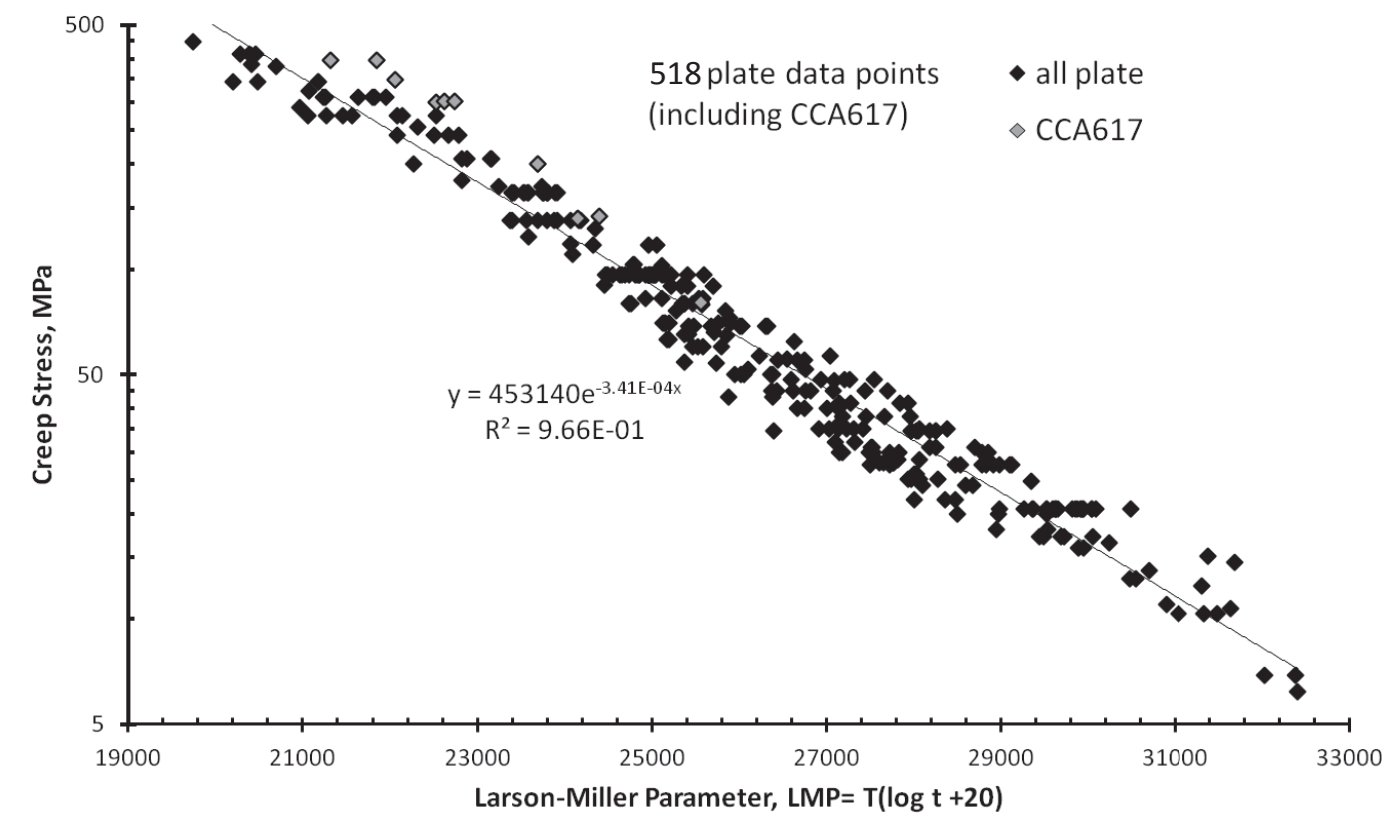

Figure 1. Larson-Miller plot for Alloy 617 base metal and weldments.

Figure 1 is typical of the current understanding of the behavior of Alloy 617. It illustrates that there is an extensive data base and the properties of contemporary heats of material exhibit properties that are consistent with historical values. For design purposes, however, characterization of the mechanical properties is not complete and must be extended to evaluate behavior in the multi-axial loading that is more typical of application. A limited amount of multi-axial testing has been done on Alloy 617 and other austenitic alloys including tension-torsion and tensile loading of pressurized tubes. ${ }^{5}$ In this report, the elevated temperature creep behavior and time to rupture of Alloy 617 plate in biaxial loading of internally pressurized tubes have been determined and will be compared to the properties of the alloy determined using traditional uniaxial loading. 


\section{MATERIAL}

Alloy 617 is strengthened by solid solution hardening provided by the alloy elements chromium, cobalt and molybdenum as well as by intra- and inter-granular carbide precipitates. The high temperature oxidation resistance is derived from the high nickel and chromium content. The material tested in the current experiments was from $3.5 \mathrm{~mm}$ thick hot rolled plate that was solution annealed and manufactured by ThyssenKrupp VDM, Inc. The alloy was prepared using induction melting, followed by electroslag remelting prior to casting the ingot. Chemistry of heat number 314626 plate reported on here is given in Table 1.

Table 1. Chemical Analysis of ThyssenKrupp VDM, Inc. heat number 314626.

\begin{tabular}{|l|l|l|l|l|l|l|l|l|l|l|l|l|l|}
\hline $\mathrm{C}$ & $\mathrm{Mn}$ & $\mathrm{Si}$ & $\mathrm{P}$ & $\mathrm{S}$ & $\mathrm{Cr}$ & $\mathrm{Ni}$ & $\mathrm{Co}$ & $\mathrm{Mo}$ & $\mathrm{Ti}$ & $\mathrm{Al}$ & $\mathrm{B}$ & $\mathrm{Cu}$ & $\mathrm{Fe}$ \\
\hline 0.05 & 0.1 & 0.1 & 0.005 & $<0.002$ & 22.2 & 54.1 & 11.6 & 8.6 & 0.4 & 1.1 & $<0.001$ & 0.04 & 1.6 \\
\hline
\end{tabular}

The as-received plate had an equiaxed grain structure with an average grain size of about $155 \mu \mathrm{m}$. Some banding was observed resulting from segregation in the original ingot; a composite optical micrograph showing the three orientations of the plate is shown in Figure 2. TEM investigation of the as-received, solution annealed Alloy 617 plate found no evidence of $\gamma^{\prime}$ precipitates in the FCC $\gamma$ matrix. The material had a low density of dislocations and did not exhibit a dislocation cell or subgrain structure. Carbides and nitrides were frequently observed that have been previously identified in Alloy 617 as $\mathrm{M}_{23} \mathrm{C}_{6}$ and $\mathrm{MC}$ carbides and TiN nitrides .

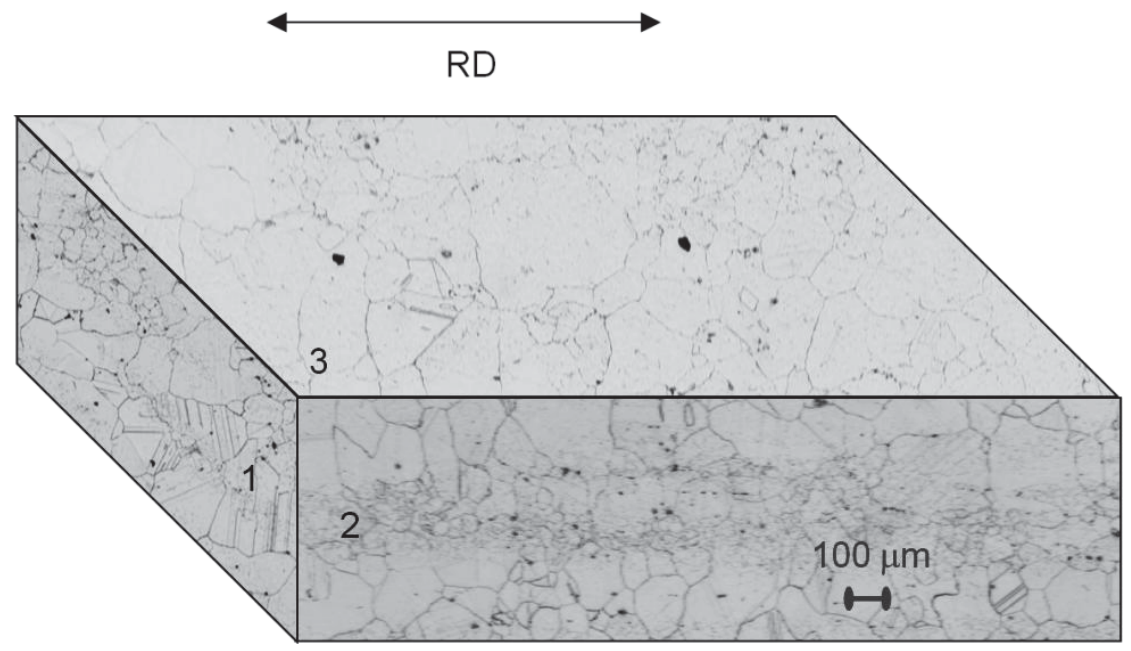

Figure 2. Optical metallography of reference plate.

\section{TEST DEVELOPMENT}

Testing has been carried out using internally pressurized Alloy 617 tubes to determine creep strain and time to rupture at $950^{\circ} \mathrm{C}$. The test specimens were machined from the VDM plate material to ensure that the material properties were directly comparable to the extensive series of experiments previously performed on this material.

The relationship of the stress in the center of a pressurized tube (away from end effects) is shown schematically in Figure 3. The von Mises yield criterion assumes that a material will start to yield when its von Mises stress, also known as the equivalent stress, exceeds the yield strength. The equivalent stress, $\sigma_{e q}$, is calculated as 


$$
\sigma_{e q}=\left(\frac{1}{2}\left(\left(\sigma_{1}-\sigma_{2}\right)^{2}+\left(\sigma_{1}-\sigma_{2}\right)^{2}+\left(\sigma_{1}-\sigma_{2}\right)^{2}\right)\right)^{\frac{1}{2}}
$$

where $\sigma_{1}, \sigma_{2}$, and $\sigma_{3}$ are the principal stresses. For the uniaxial stress state, $\sigma_{e q}=\sigma_{1}$, the applied tensile strength. The center of a pressurized tube is in a biaxial stress state if it was a relatively thin wall, as the radial stress approaches zero at the outer diameter. The relationship between pressure and stresses in the tube are given as $\sigma_{\mathrm{h}}=\mathrm{pd} / 2 \mathrm{t}$, and $\sigma_{\mathrm{a}}=\mathrm{pd} / 4 \mathrm{t}$, where $\sigma_{\mathrm{h}}$ and $\sigma_{\mathrm{a}}$ are the hoop and axial stresses, respectively, $\mathrm{p}$ is the internal pressure, $\mathrm{d}$ is the diameter and $\mathrm{t}$ is the wall thickness of the cylinder. Since the hoop stress is twice the axial stress, the hoop strain, as indicated by the change in circumference, is of primary interest; however, it is equivalent to the change in diameter, as indicated in Figure 3. The material is expected to fail when the maximum principal stress or strain exceeds the maximum stress or strain determined in a uniaxial test. A detailed analysis of the stresses and associated strains in both thick and thin walled tubes has been published for Alloy $617 .^{5}$

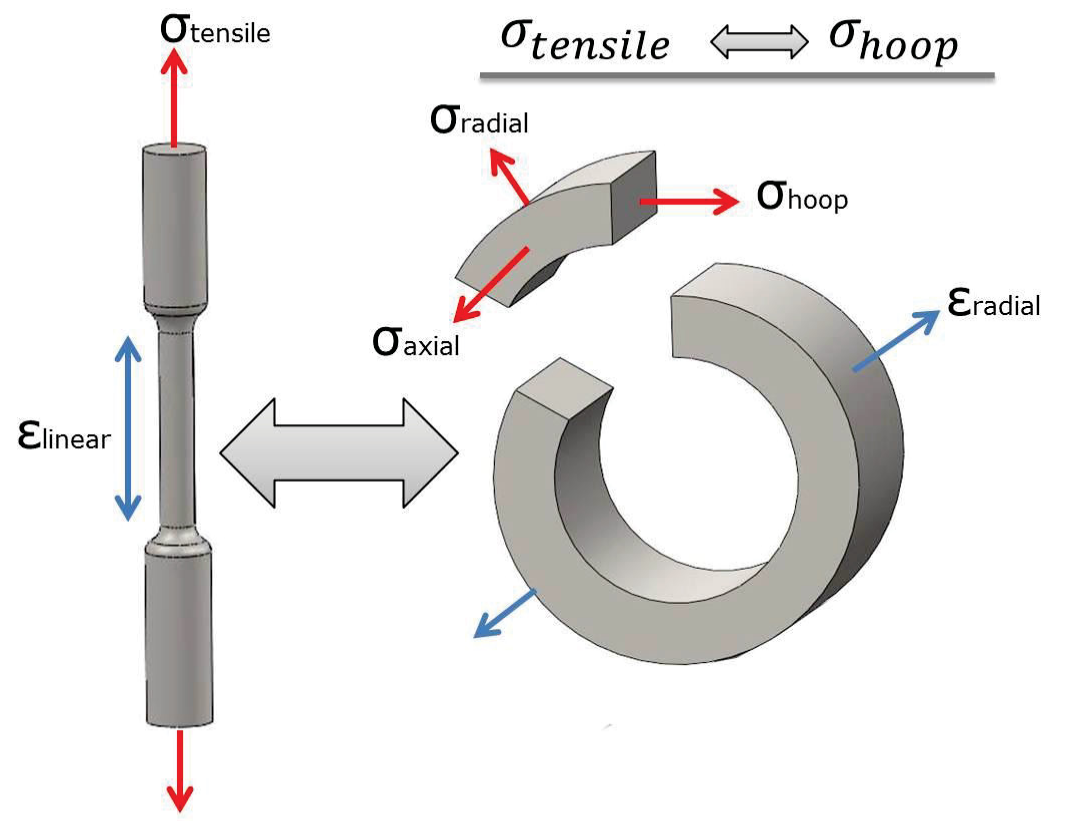

$$
\varepsilon_{\text {linear }}=\frac{\Delta L}{L_{o}} \approx \frac{\Delta C}{C_{o}}=\frac{\pi \Delta D}{\pi D_{o}}=\frac{\Delta D}{D_{o}}=\varepsilon_{\text {radial }}
$$

Figure 3. Schematic comparing stress in a tensile test to stress in a pressurized tube.

A finite element model was developed to simulate creep deformation in an internally pressurized tube to define a test specimen with a well understood stress state to which an appropriate stress could be applied with manageable internal pressure. The geometry used for the FEM simulation is shown in Figure 4, and an example of a simulation for a specimen crept at $950^{\circ} \mathrm{C}$ is shown in Figure 5. 


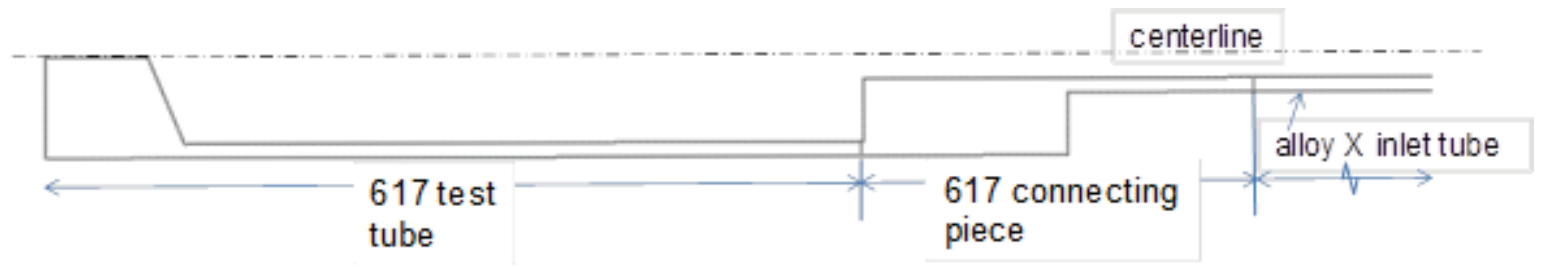

Figure 4. Specimen geometry simulated using a finite element model.

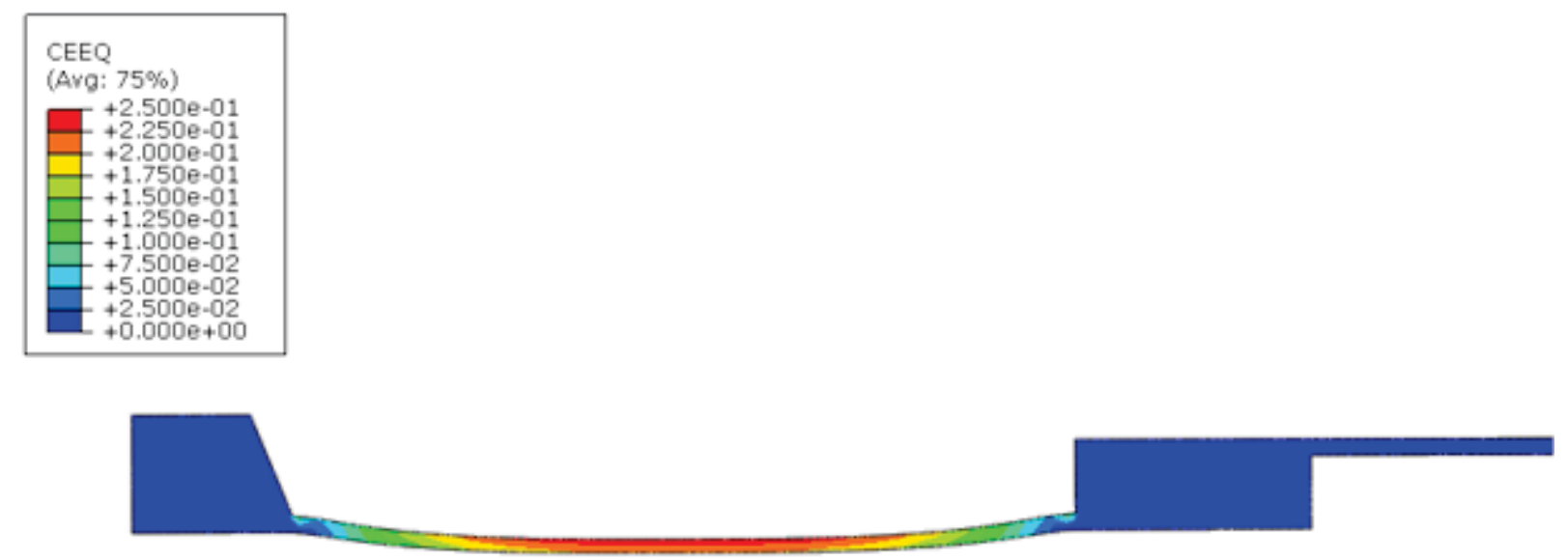

Figure 5. Finite element simulation of an Alloy 617 test specimen crept at $950^{\circ} \mathrm{C}$.

As a result of the simulations, it was determined that tubes with an external diameter of $12.7 \mathrm{~mm}$ and length of approximately $65 \mathrm{~mm}$ resulted in nearly uniform deformation in the center region. Very little strain occurred at the corners or in the end caps, provided the ends are significantly thicker than the tube walls. This geometry allowed internal pressures of approximately $5.3 \mathrm{MPa}(500 \mathrm{psi})$ to be applied, to result in a hoop stress in the desired range for creep testing at $950^{\circ} \mathrm{C}$. At this temperature a significant amount of conventional creep data is available from both this program and the literature. Ultimately, several tube diameters with varying wall thickness were examined, shown in Table 2 . The inlet tube used to pressurize the test specimen was thin wall hot drawn Hastelloy X that was $3 \mathrm{~mm}$ in diameter. This tube was welded to an Alloy 617 junction piece that was in turn welded to the specimen tube. FEM indicated that by using small diameter tube it was possible to reduce the hoop stress in this piece such that creep did not occur during a typical test duration.

Table 2. Specimen geometries tested.

\begin{tabular}{|c|c|c|c|}
\hline \multicolumn{4}{|c|}{ Sample Geometries } \\
\hline Dimension & Geometry A & Geometry B & Geometry C \\
\hline Diameter (in/mm) & $0.50 / 12.70$ & $0.75 / 19.05$ & $0.75 / 19.05$ \\
\hline Length (in/mm) & $2.0 / 63.5$ & $2.0 / 63.5$ & $2.0 / 63.5$ \\
\hline Thickness (in/mm) & $0.035 / 0.89$ & $0.039 / 1.00$ & $0.079 / 2.00$ \\
\hline
\end{tabular}

A piping and instrumentation diagram for the test system is shown in Figure 6 . The system was configured for active control of the helium pressure during a test. In normal operation the pressure operated in a quasi-steady state. The control system was designed such that the test was automatically terminated if the volume of gas added to maintain the tube pressure exceeded a predetermined set point 
that was considered an indication of a tube failure. A typical record of the temperature and gas pressure during a test segment is shown in Figure 7. The setpoint for this test was 5.3MPa (775 psig) and the controller maintained the pressure within $\pm 34.3 \mathrm{~Pa}(5 \mathrm{psi})$ of the set point; the temperature was controlled to within $\pm 2^{\circ} \mathrm{C}$. It can be seen in the figure that tube failure was associated with frequent cycles in the gas pressure that eventually caused an excursion beyond acceptable values and automatically terminated the test.

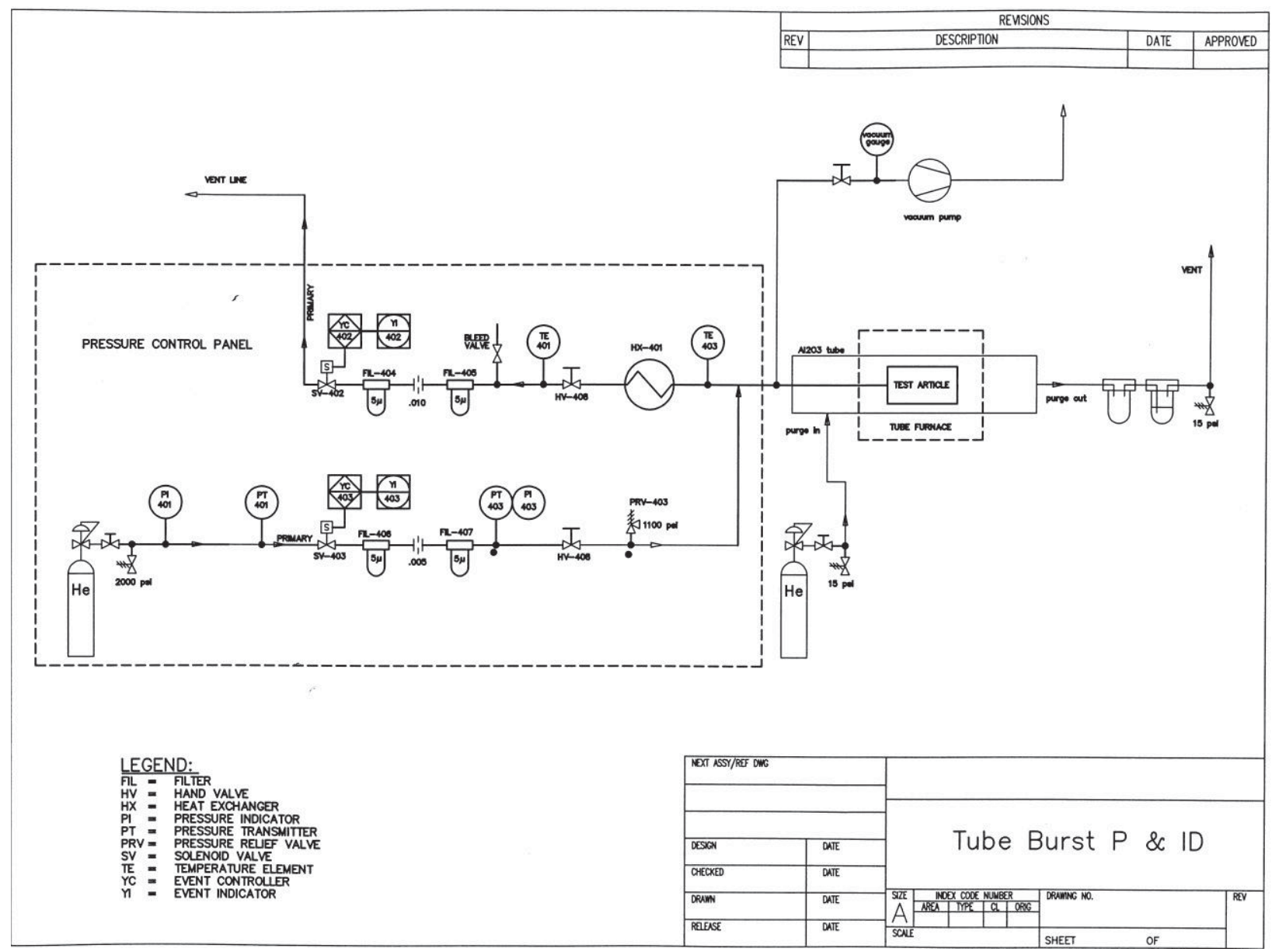

Figure 6. Piping and instrumentation diagram for gas control system. 


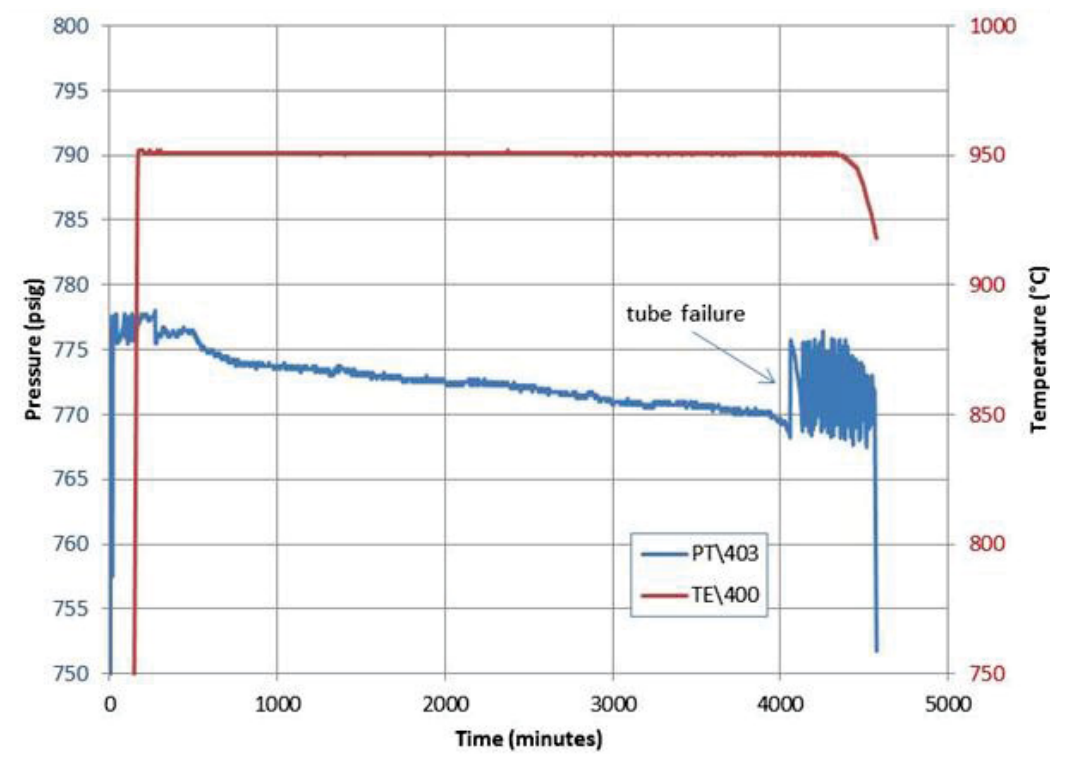

Figure 7. Measured temperature and gas pressure during a test segment.

The specimen was brought to ambient temperature and pressure at 100 hour intervals for the purpose of periodically measuring the diameter to monitor creep as the test progressed. The diameter measurements were made with a digital micrometer at uniform intervals along the length of the tube to determine the variability in strain along the length. Measurements were also made at two axial locations, $90^{\circ}$ apart, to account for variability in the diameter associated with the specimen fabrication. The diameter of the nondeforming end plug on the sample was measured after each test interval and any increase in the diameter was used as an indication of oxidation; diameters in the deformed section were corrected for oxide growth using this measurement.

Several tests were carried out at Boise State University (BSU) as part of a senior design project. For these experiments a similar test configuration was used, however, the gas pressure was monitored and controlled manually. Temperature and pressure were held to the same tolerances in these tests as the automated system described above. The test increment in this case was 40 hours and the specimen diameter was measured using a laser based gage.

\section{CONSTITUTIVE MODEL DEVLEOPMENT Creep Behavior}

In order to model the creep behavior of Alloy 617 in the FEM simulations used to design the specimens, it was necessary to develop a constitutive model of the creep behavior. In the course of developing the creep constitutive model it was determined that the behavior of Alloy 617 at $750^{\circ} \mathrm{C}$ was significantly different compared to higher temperatures. This is significant for ASME Code qualification because understanding the mechanism(s) of deformation is necessary to confidently extrapolate the properties into regions that have not been characterized experimentally. It should also be noted that a version of Alloy 617 that has been modified to accentuate strengthening from $\gamma^{\prime}$ at temperatures of $750^{\circ} \mathrm{C}$ and below has been developed for fossil energy applications. ${ }^{4}$ Thus, a portion of this report will be dedicated to discussing the lower temperature creep behavior of Alloy 617 before returning to discussion of the pressurized tube creep results.

It is well known that nickel alloys of this type do not exhibit extensive steady state creep, however, this approach is commonly used and is the most convenient first approximation. Determination of the 
relationship of minimum creep rate to time to rupture, the Monkman-Grant relationship, is also very useful for design calculations. For solid solution single phase alloys the minimum creep rate, $\dot{\varepsilon}_{\text {min }}$, is typically described by a modified power-law relationship: ${ }^{6-8}$

$$
\dot{\varepsilon}_{\min } \propto D \frac{? b}{k T}\left(\frac{\sigma}{\text { 早 }}\right)^{n}
$$

where $\mathrm{D}$ is the diffusion coefficient of the matrix, $\sigma$ is the applied stress, $\mu$ is the shear modulus, $\mathrm{b}$ is the Burgers vector, $\mathrm{k}$ is the Boltzman constant and $\mathrm{T}$ is the temperature. ${ }^{9-11}$ The stress exponent, $\mathrm{n}$, is accepted to be in the range of 3 to 5 for solid solution alloys and, more specifically, around 5 for nickel and nickelchromium alloys. ${ }^{10,13,14}$

The creep behavior of solution-annealed Alloy 617 is characterized by short periods of both primary and secondary creep, followed by a tertiary creep regime, which comprises the majority of the total creep life. This is illustrated by the strain versus time plots for the creep tests at $750^{\circ} \mathrm{C}$ for stresses of 121 and 145 $\mathrm{MPa}$, shown in Figure 8, which were interrupted at approximately $20 \%$ strain. Although, strain versus time data for all stress/temperature combinations is not shown, the general progression of creep deformation does not deviate from the characteristics of the curves in Figure 8 for varying stress or temperatures up to $1000{ }^{\circ} \mathrm{C}$. The minimum creep rates for the investigated temperatures are plotted against the applied stress on a log-log scale in Figure 9, the slope representing the stress exponent, $n$, in power law creep. The stress exponent, $n$, ranges from 8.3 to 5.1 and decreases with increasing temperature from 750 to $1000{ }^{\circ} \mathrm{C}$. The stress exponent for $750,800,900$, and $1000{ }^{\circ} \mathrm{C}$ individually is 8.3 , $6.9,5.9$, and 5.1, respectively.

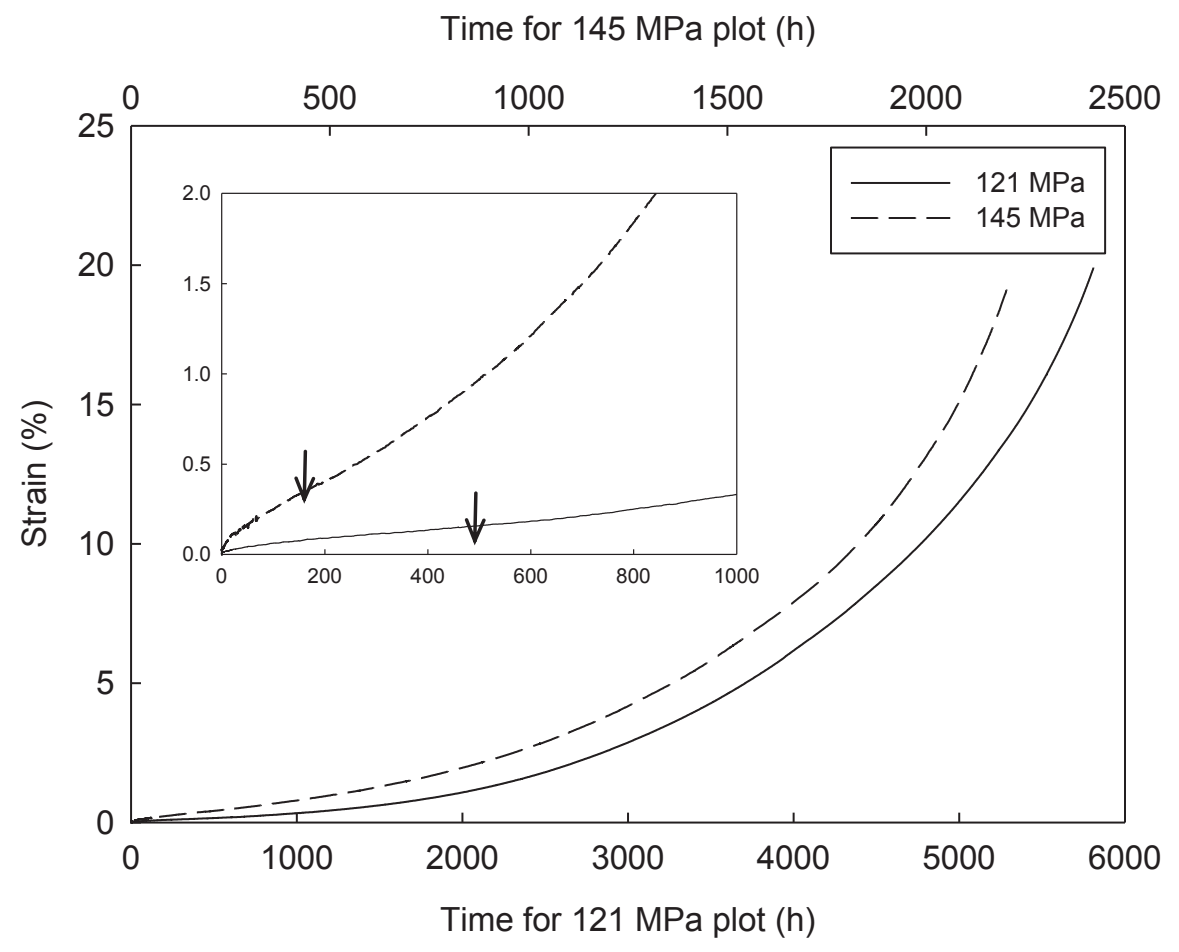

Figure 8. Strain versus time of Alloy $617 \mathrm{crept}$ at $750{ }^{\circ} \mathrm{C}$ and $121 \mathrm{MPa}$ and $145 \mathrm{MPa}$ and interrupted at approximately $20 \%$ total strain. The large plot presents the 121 and $145 \mathrm{MPa}$ data to test termination on separate time axis (121 MPa on bottom and $145 \mathrm{MPa}$ on top) to highlight the similarity in shape. The inset plots the data on a single time axis up to 1000 hours to show the primary creep region at each stress and highlight the creep rates. Arrows on the inset plot indicate the minimum creep rate determined from a mathematical minimum of a curve fit to the digital experimental data. 


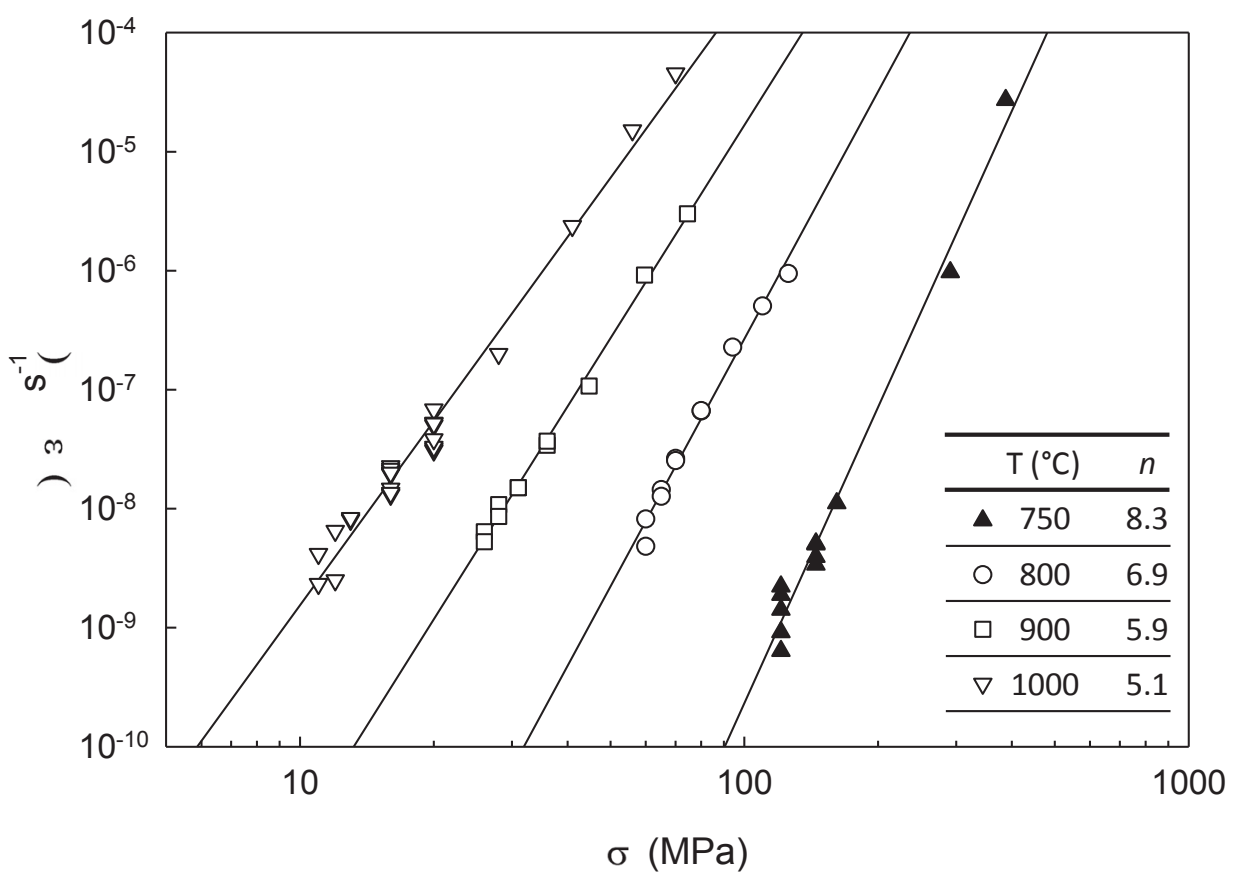

Figure 9. Minimum creep rate as a function of stress showing a stress exponent, $n$, ranges from 5.1 at $1000^{\circ} \mathrm{C}$ to 8.3 at $750{ }^{\circ} \mathrm{C}$.

\section{Zener-Hollomon Analysis}

There are several approaches to normalizing creep data so that experimental results from a wide range of stresses and temperatures and stresses can be displayed on a single plot; the approach described by Zener and Hollomon is described in this section. ${ }^{17}$ The minimum creep rate defined by Eq. [2] may be described in more of an engineering form through the Norton equation as

$$
\dot{\varepsilon}_{\min }=\dot{\varepsilon}_{0}\left(\frac{\sigma}{\sigma_{0}}\right)^{n}
$$

where $\dot{\varepsilon}_{\text {min }}$ is the minimum creep rate, $\dot{\varepsilon}_{0}=B \exp \left(-Q_{c} /_{R T}\right)$, and $\sigma_{0}$ is a reference stress. The reference stress may be replaced by the Young's, E, or shear modulus, $\mu$, when $\mathrm{T} / \mathrm{T}_{\mathrm{m}}>0.6$ and the activation energy for creep, $Q_{c}$, is essentially equal to the activation energy for self-diffusion. ${ }^{10,15,16}$ Rearranging Eq. [3], minimum creep rates at multiple temperatures may then be compared utilizing a plot of the modulus corrected stress versus the Zener-Hollomon parameter ${ }^{17}, \mathrm{Z}$, defined as

$$
Z=\dot{\varepsilon}_{\min } \exp \left(\frac{Q_{c}}{R T}\right)=\mathrm{B}\left(\frac{\sigma}{E}\right)^{n}
$$

An activation energy, $Q_{c}$, of approximately $410 \mathrm{~kJ} / \mathrm{mol}$ was determined to give the best fit to the Alloy 617 experimental data in Figure 10. From this plot, the value of $Z$ for experimental creep data at temperatures between 800 through $1000{ }^{\circ} \mathrm{C}$ fit on the same regression line with $n$ of 5.6 indicating that the creep behavior is characterized by a single power law creep equation. The $750{ }^{\circ} \mathrm{C}$ creep data clearly reside adjacent to the regression line and exhibits a significantly higher slope with $n$ of 8.3. It is known that precipitation of $\gamma^{\prime}$ occurs only at this temperature, which is likely to be the reason that these data are not well represented by the normalized data for higher temperatures. A detailed analysis of strengthening from this phase is presented below. 


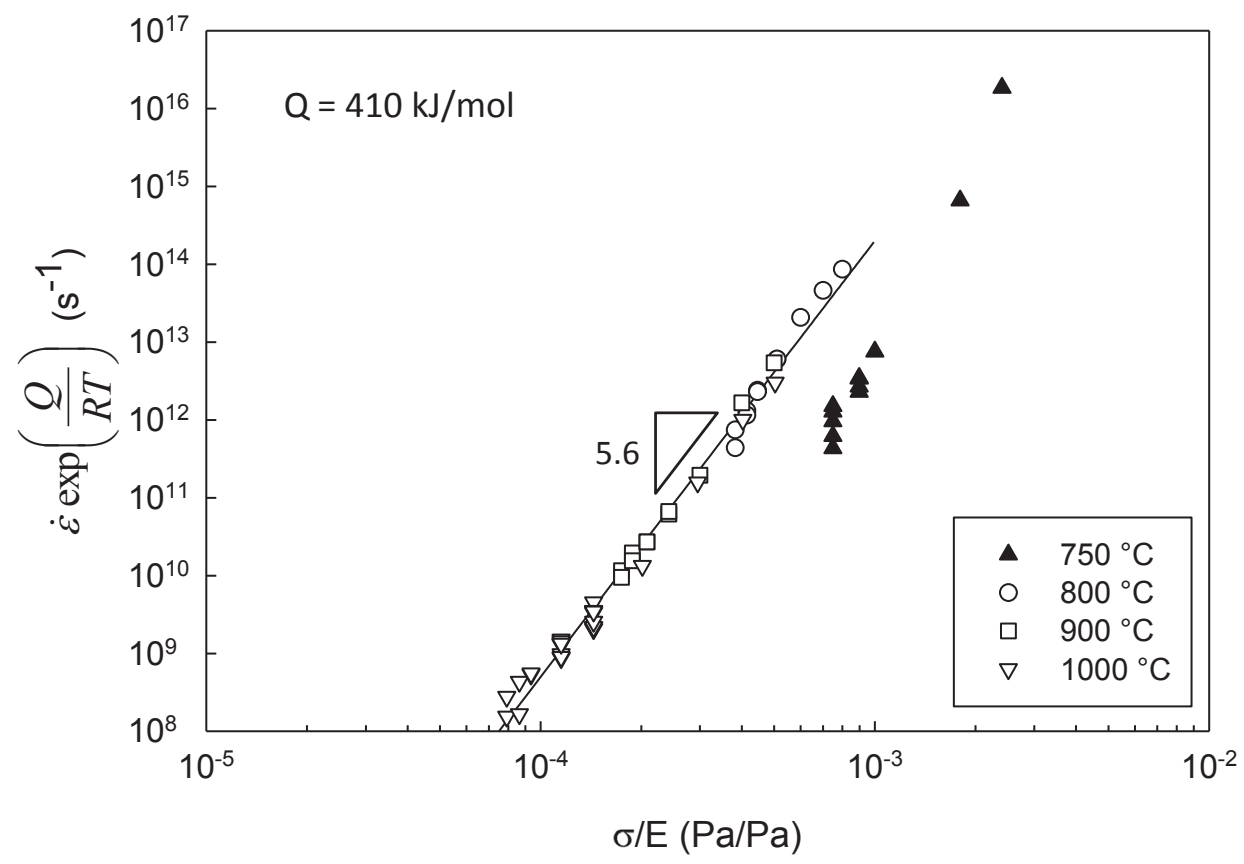

Figure 10. Zener-Hollaman plot of minimum creep rates from at $750,800,900$ and $1000{ }^{\circ} \mathrm{C}$. The $750{ }^{\circ} \mathrm{C}$ data is offset to the right of the data at the other temperatures indicating threshold stress behavior.

\section{Characterization of $y^{\prime}$ Formation}

Alloy 617, is predominately a solid solution alloy strengthened by additions of Co and Mo, however, it does contain low levels of $\mathrm{Al}$ and $\mathrm{Ti}$ that form $\mathrm{Ni}_{3} \mathrm{Al} \gamma^{\prime}$ precipitates at intermediate temperatures. ${ }^{18}$ The precipitated $\gamma^{\prime}$ is present in very low volume fractions at sizes best imaged by transmission electron microscopy (TEM) and the $\gamma^{\prime}$ does not persist in any appreciable amount at temperatures above $850{ }^{\circ} \mathrm{C}$. In this section of the report the formation of $\gamma^{\prime}$ in furnace aged material will be described because it is convenient to do detailed analysis in the absence of deformation. Analysis of $\gamma^{\prime}$ formation and interactions with dislocations in the gage section of samples deformed in creep will be discussed in the following section.

As noted above, TEM investigation of the as-received, solution annealed Alloy 617 plate found no evidence of $\gamma^{\prime}$ precipitates in the FCC $\gamma$ matrix. The material had a low density of dislocations and did not exhibit a dislocation cell or subgrain structure. Carbides and nitrides were frequently observed and have been previously identified in Alloy 617 as $\mathrm{M}_{23} \mathrm{C}_{6}$ and $\mathrm{MC}$ carbides and TiN nitrides. ${ }^{18}$

After as little as two hours of static aging at $750^{\circ} \mathrm{C}$, spherical $\gamma^{\prime}$ precipitates averaging $9 \mathrm{~nm}$ in radius are present. Additional aging at $750{ }^{\circ} \mathrm{C}$ results in an increasing particle volume fraction, then to significant coarsening and ultimately to spherical to cuboidal shape evolution, as shown in Figure 11 (a)-(c). Selected area diffraction is consistent with the precipitates having the $\mathrm{L}_{2}$ lattice structure, indicative of the ordered FCC $\gamma^{\prime}$ phase, as illustrated by a $<111>$ zone axis in Figure 11 (d). The average $\gamma^{\prime}$ precipitate radii are given in Table 3 along with the area fractions and calculated volume fractions. The volume fraction of $\gamma^{\prime}$ saturates after approximately 5300 hours of aging. 

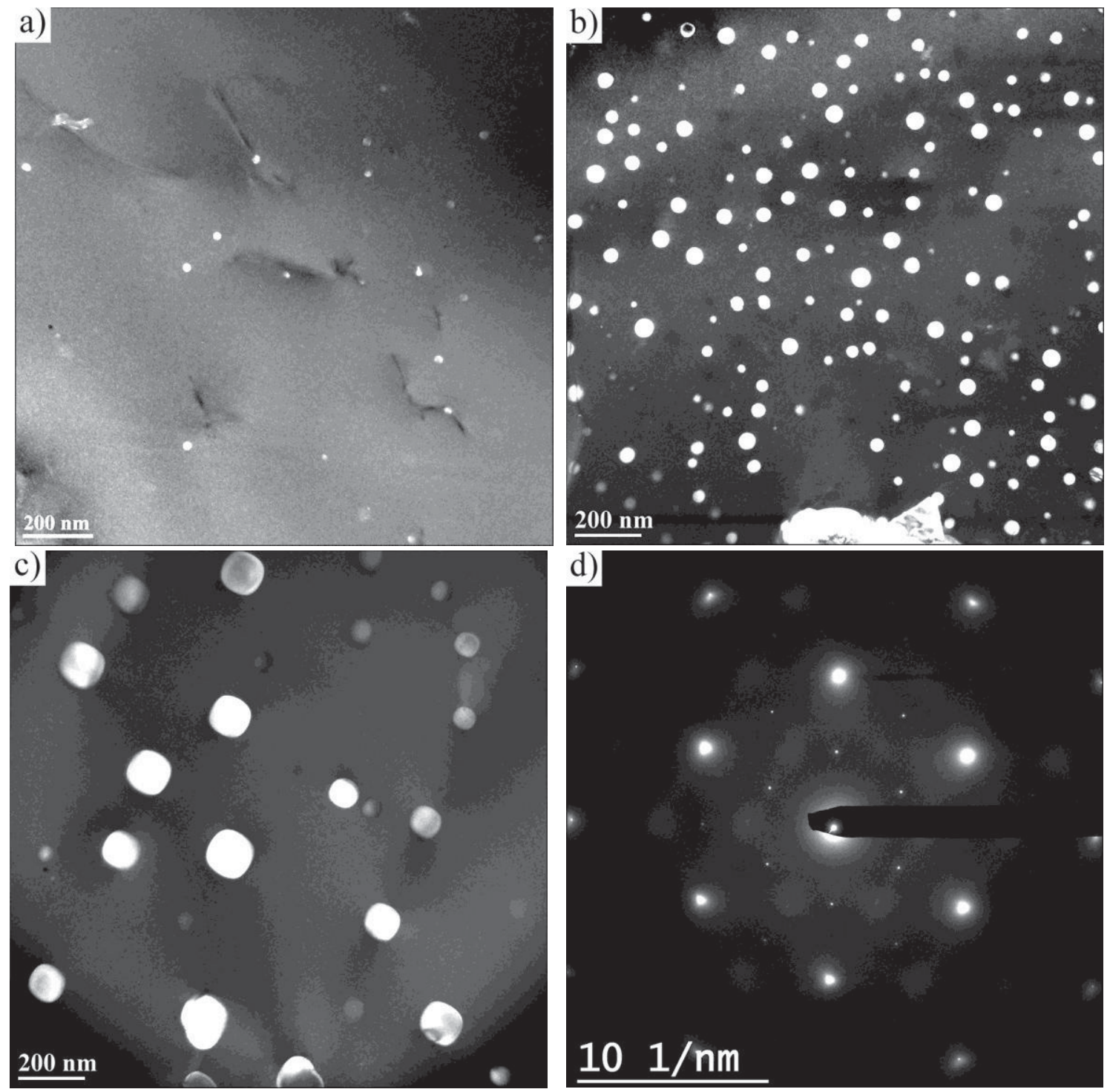

Figure 11. Typical $\gamma^{\prime}$ precipitates imaged after static aging at $750{ }^{\circ} \mathrm{C}$ for a) $2 \mathrm{hrs}$, b) $200 \mathrm{hrs}$ and c) 5300 hrs. Superlattice reflections evident in the $<111>$ zone axis diffraction pattern representative of the ordered $\mathrm{L}_{2} \gamma^{\prime}$ precipitates $(\mathrm{d})$. 
Table 3. $\gamma^{\prime}$ Area and Volume Fractions at Various Static Aging Times at $750{ }^{\circ} \mathrm{C}$

\begin{tabular}{llll}
\hline Aging Time & $\begin{array}{l}\text { Average Radius \% Area } \\
(\mathrm{nm})\end{array}$ & $\begin{array}{l}\text { \% Vol. (Calculated with } \\
100 \mathrm{~nm} \text { foil thickness) }\end{array}$ \\
\hline 200 & 17 & 7.6 & 1.4 \\
\hline 650 & 31 & 6.2 & 1.8 \\
\hline 2000 & 43 & 5.3 & 1.9 \\
\hline 5300 & 51 & 6.2 & 2.5 \\
\hline 20000 & 80 & 5.3 & 2.7 \\
\hline
\end{tabular}

The interface between the $\gamma$ matrix and the $\gamma^{\prime}$ prime precipitate was investigated to evaluate coherency of the $\gamma^{\prime}$ precipitates by utilizing weak beam TEM to image misfit dislocations, if present, at the interface. Weak beam images were acquired with two $<200>$-type g-vectors near the $<001>$ zone axis since the misfit dislocations in $\gamma-\gamma^{\prime}$ nickel alloys are of the type, a/2<110>. ${ }^{19,20}$ Dislocation contrast is expected in one of the weak beam images since $\mathbf{g} \cdot \mathbf{b}$ will be non-zero for at least one of the $<200>$-type reflections. Despite reports of prolonged aging promoting the loss of coherency of the gamma prime particles ${ }^{19}$, dislocations were not found at the $\gamma / \gamma^{\prime}$ interface in any of the statically-aged samples, as shown in Figure 12 for material aged at $750{ }^{\circ} \mathrm{C}$ for $20,000 \mathrm{hrs}$. 

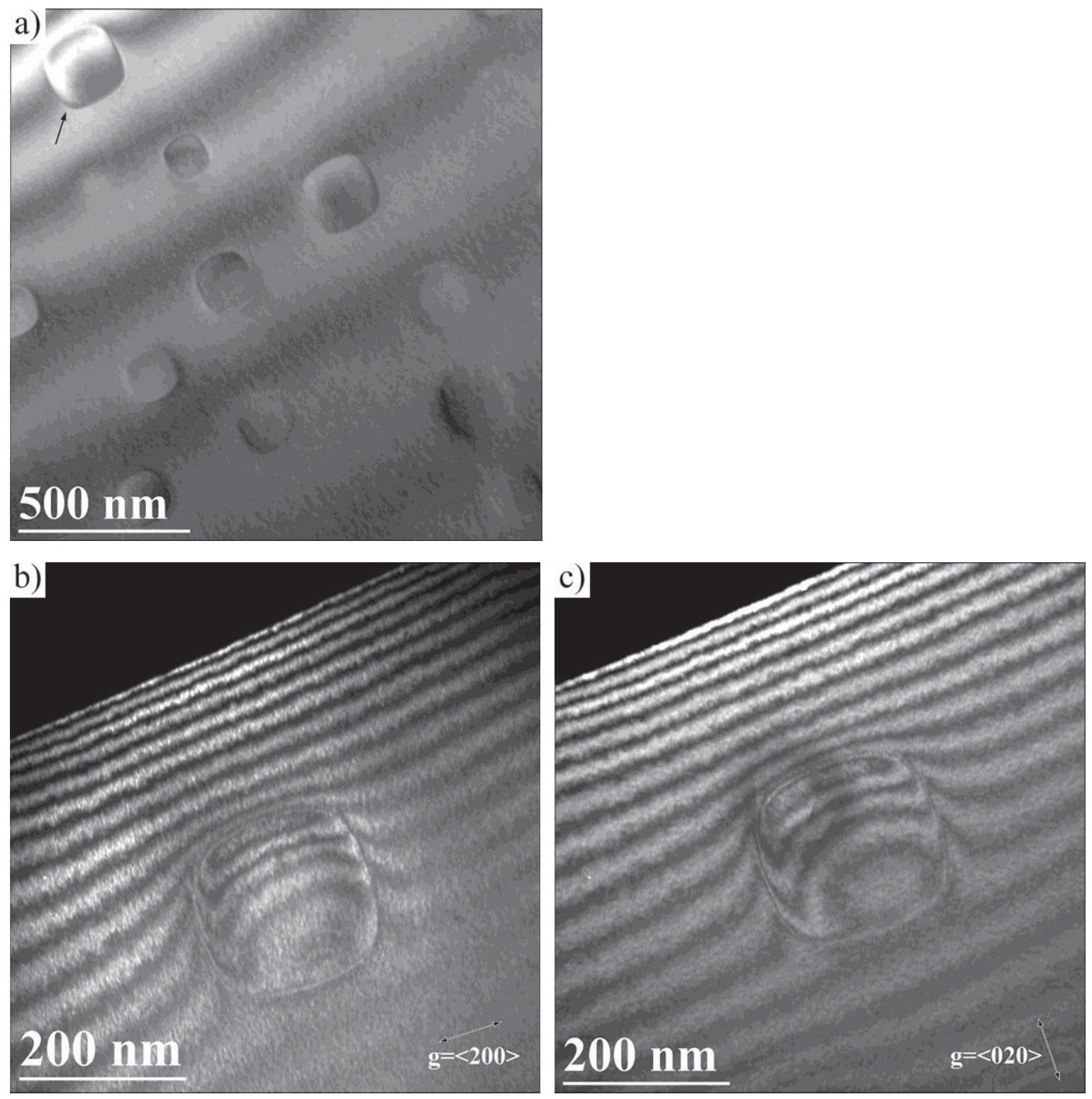

Figure 12. a) Bright field, b) weak beam, $g=<200>$ and c) weak beam, $g=<020>$, images of $\gamma^{\prime}$ precipitates in the sample aged at $750{ }^{\circ} \mathrm{C}$ for $20,000 \mathrm{hr}$. No dislocation contrast is seen in either weak beam image indicating the $\gamma^{\prime}$ particles remain coherent even after the long term aging heat treatment.

\section{Crept Microstructures}

Elucidating the mechanism of strengthening by $\gamma^{\prime}$ requires detailed analysis of the interaction of particles and dislocations after creep deformation, as discussed here. TEM was performed on material taken in the longitudinal orientation from the gage length of crept uniaxial specimens in order to investigate the influence of the $\gamma^{\prime}$ particles on the creep behavior. Representative TEM micrographs from the specimens crept at $750{ }^{\circ} \mathrm{C}$ under an applied stress of $121 \mathrm{MPa}$ and $145 \mathrm{MPa}$ at interrupted creep strains of $2 \%, 5 \%$, and $10 \%$ are shown in Figure 13. A bright field image with $\mathbf{g}=<200>$ is included for each condition. In general, the dislocation density remains fairly low, even up to creep strains of 5\%, which is well into the tertiary creep regime in Figure 8. It should also be noted that an organized dislocation cell substructure was not observed. The effect of applied stress on $\gamma^{\prime}$ particle shape appears to be relatively 
minor with the particles remaining relatively spherical up to a creep strain of 5\%. Beyond 5\% creep strain, the shape of the particles begins to deviate significantly from spherical, as shown in Figure 14. Additionally, it was found that the $\gamma^{\prime}$ particle size in the crept material fell within the statistical error of that found during static aging, even at creep strains of $10 \%$ where deviations in particle shape are observed.

The TEM investigation of the crept microstructures also revealed evidence of at least two creep mechanisms at work during creep at $750^{\circ} \mathrm{C}$. Both Orowan looping (white arrows) as well as local dislocation climb (black arrow) are evident following $2 \%$ creep strain at $750{ }^{\circ} \mathrm{C}$ and an applied stress of $121 \mathrm{MPa}$, as shown in the top, left images in Figure 15. In general, evidence for these two creep mechanisms is also found at both 5 and $10 \%$ creep strain at the $121 \mathrm{MPa}$ condition while the dislocation density remains approximately the same, as shown in the left column in Figure 15. Following creep deformation at $145 \mathrm{MPa}$ and $750{ }^{\circ} \mathrm{C}$, evidence of Orowan looping is lacking and only simple interaction with the $\gamma^{\prime}$ particle, manifested as local dislocation climb, is observed at creep strains of 2 and $5 \%$, illustrated in the top, right and middle, right images in Figure 15. At 10\% creep strain, the dislocation density has greatly increased compared to the specimen tested to $10 \%$ creep strain at $121 \mathrm{MPa}$.

There is a significant difference in $\gamma^{\prime}$ particle size during the creep tests at the two different applied stresses. The tests run at $145 \mathrm{MPa}$ required less than half as much time to achieve the same creep strain as those run at $121 \mathrm{MPa}$, resulting in more $\gamma^{\prime}$ particle coarsening in $121 \mathrm{MPa}$ tests. Table 4 quantitatively shows a significantly smaller $\gamma^{\prime}$ particle size $(\sim 19 \%$ smaller $)$ in the material tested at $145 \mathrm{MPa}$ relative to that tested at $121 \mathrm{MPa}$ as a result of the shorter test duration. This finer $\gamma^{\prime}$ particle size for a relatively constant volume fraction gives rise to smaller particle spacing, which is inversely related to the Orowan looping stress. As a consequence, the presence of dislocation loops around the particles after $2 \%$ creep strain at $121 \mathrm{MPa}$ may be a direct consequence of $\gamma^{\prime}$ particle growth sufficiently reducing the Orowan looping stress allowing looping to become operative at a creep strain at which it is not active at the higher stress condition. The general absence of precipitate shearing and minimal dislocation looping indicative of Orowan bowing suggests that for continued creep deformation, the gliding dislocations are climbing around the impeding $\gamma^{\prime}$ precipitates.

Table 4. Influence of Applied Stress on Creep Test Duration and $\gamma^{\prime}$ Precipitate Radius

\begin{tabular}{cccc}
\hline $\begin{array}{c}\text { Interrupted Creep } \\
\text { Strain (\%) }\end{array}$ & $\begin{array}{c}\text { Applied } \\
\text { Stress (MPa) }\end{array}$ & $\begin{array}{c}\text { Test } \\
\text { Duration (h) }\end{array}$ & $\begin{array}{c}\gamma^{\prime} \text { Precipitate } \\
\text { Radius (nm) }\end{array}$ \\
\hline 2 & 121 & 1626 & 36 \\
& 145 & 787 & 29 \\
\hline \multirow{2}{*}{5} & 121 & 2866 & 43 \\
& 145 & 1083 & 32 \\
\hline \multirow{2}{*}{10} & 121 & 4753 & 39 \\
\hline
\end{tabular}




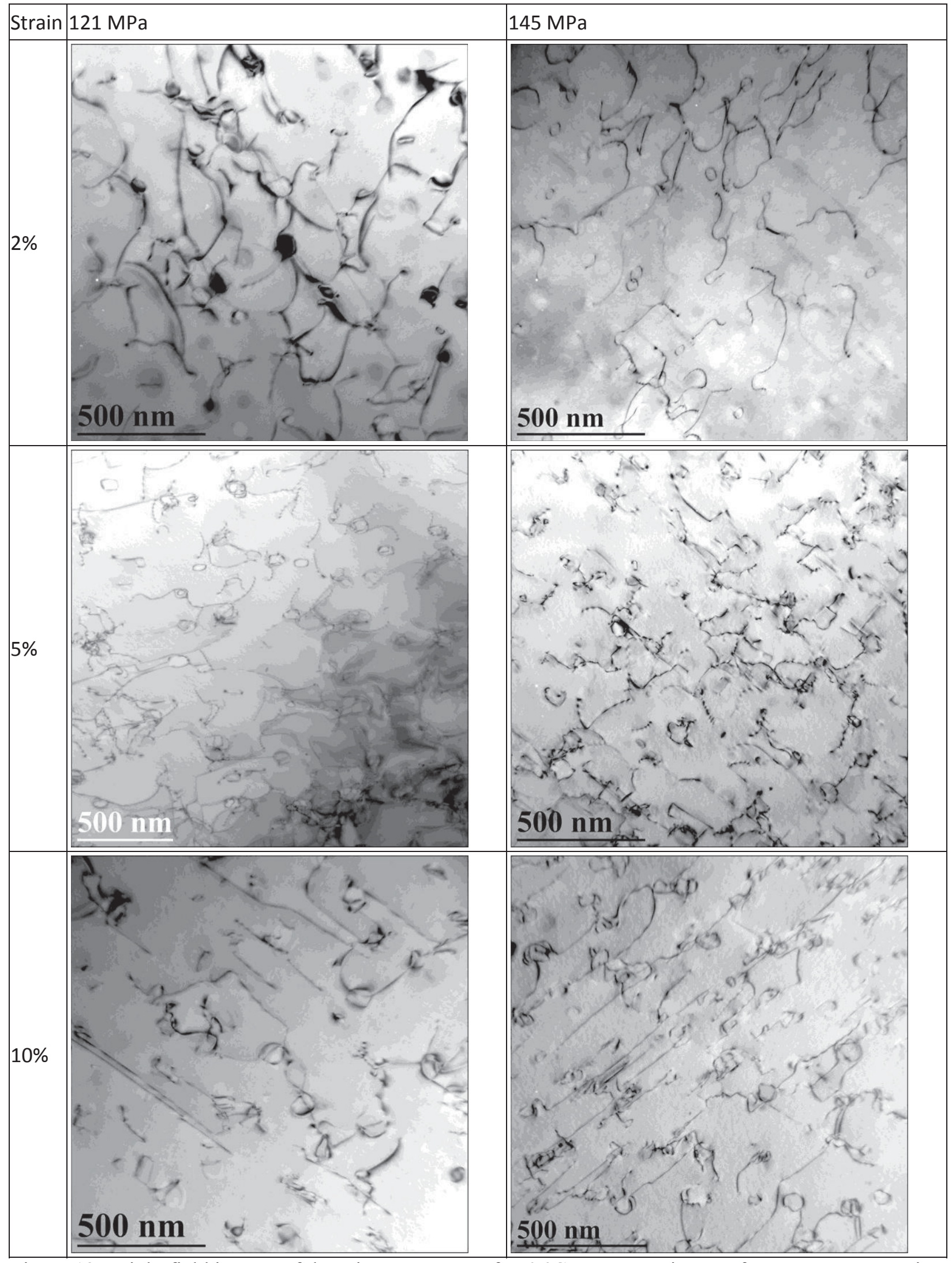

Figure 13. Bright field images of the microstructures of $750{ }^{\circ} \mathrm{C}$ creep specimens after target creep strains of $2 \%$ (top), 5\% (middle) and 10\% (bottom) at either 121 (left column) or $145 \mathrm{MPa}$ (right column). 

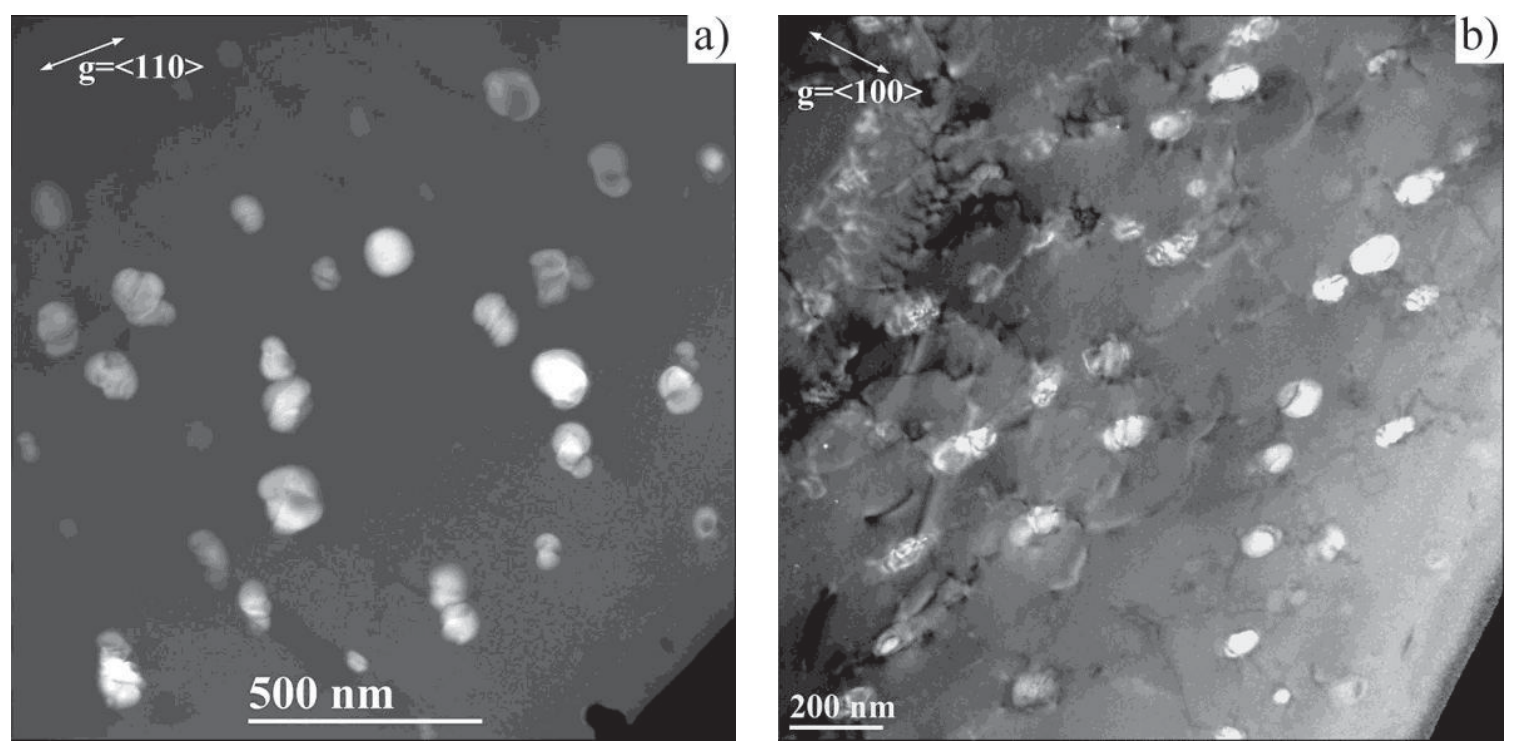

Figure 14. The $\gamma^{\prime}$ particle shape deviates significantly from spherical after creep strains of approximately $10 \%$ in $750{ }^{\circ} \mathrm{C}$ creep tests run at a) $121 \mathrm{MPa}$ and b) $145 \mathrm{MPa}$. 


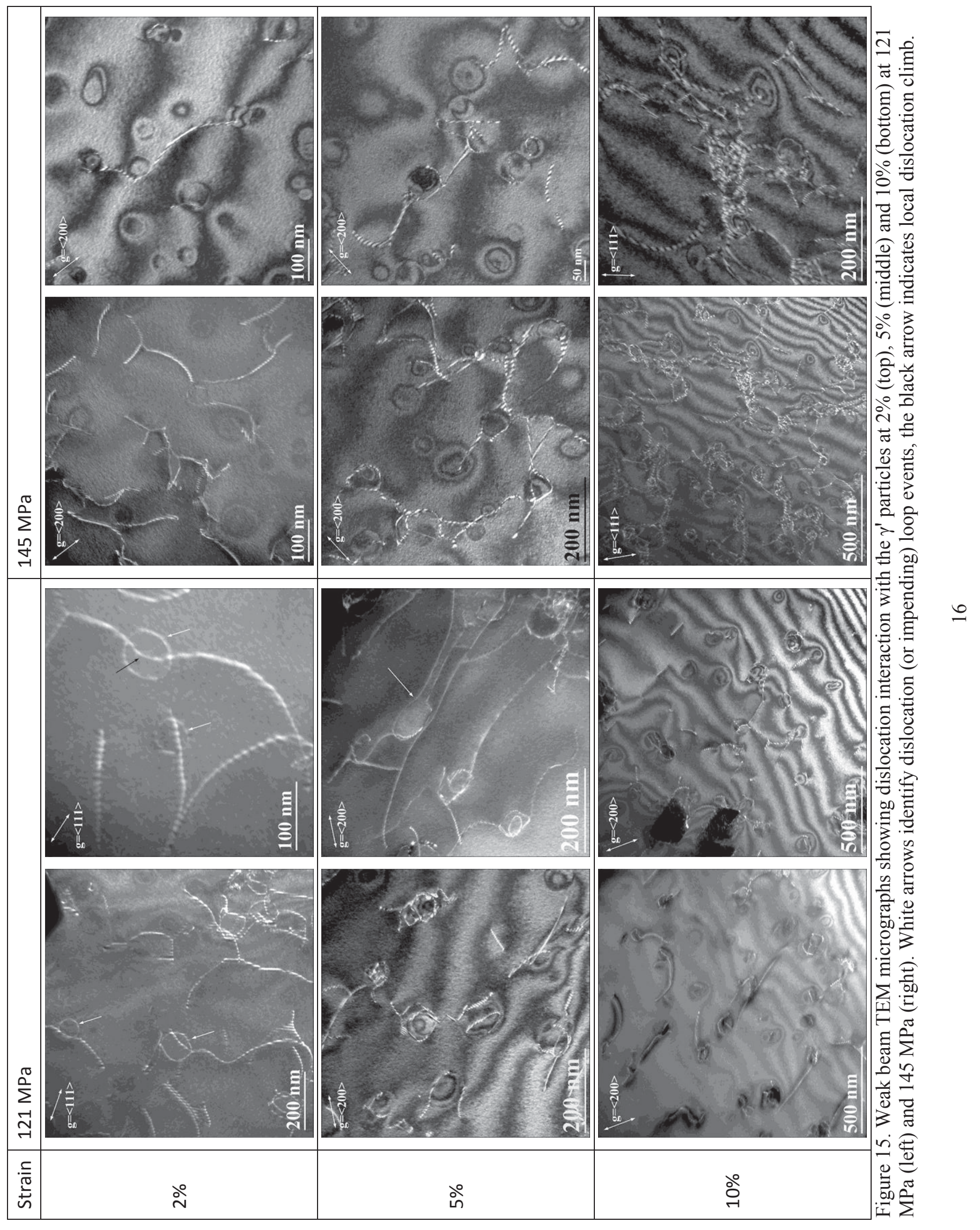


For precipitate-strengthened alloys such as Alloy 617 aged to contain $\gamma^{\prime}$, the values of $n$ and the activation energy, Q, contained in the diffusion coefficient, predicted by the fit of Eq. [2] to experimental creep data are unrealistically large compared to the range of $n$ values for solid solution alloys and the activation energy for self-diffusion. ${ }^{21,22}$ To overcome this, a threshold stress term, $\sigma_{0}$, is introduced into Eq. [2] that accounts for the influence of the precipitates on mobile dislocations and results in the following equation

$$
\dot{\varepsilon}_{\min } \propto D \frac{? b}{k T}\left(\frac{\sigma-\sigma_{o}}{?}\right)^{n}
$$

to describe the minimum creep behavior. ${ }^{8,23}$ The value of the threshold stress is dependent on the dominant precipitate bypass mechanism, which may be shearing, Orowan bowing, or climb. ${ }^{24}$ The bypass mechanism may be determined experimentally by fitting associated creep data.

Threshold behavior is commonly observed in $\gamma-\gamma^{\prime}$ superalloys ${ }^{25}$ and oxide-dispersion strengthened (ODS) alloys. ${ }^{8,23}$ The former system often exhibits a larger volume fraction of semi-coherent precipitates and the latter typically contains relatively fine, incoherent precipitates. There are few alloy systems available that allow the study of low volume fractions (less than 12\%) of coherent or semi-coherent precipitates on high temperature creep. Inconel 718 is a low volume fraction $\gamma^{\prime}$-containing superalloy, which exhibits a threshold stress of a magnitude dependent on the dislocation-precipitate bypass mode, inherently tied to precipitate size. ${ }^{25} \mathrm{~A}$ second example is aluminum alloys strengthened by coherent $\mathrm{Al}_{3} \mathrm{Sc}$ precipitates. In this case, the apparent creep threshold stress has been related to the passage of dislocations by general climb around the $\mathrm{Al}_{3} \mathrm{Sc}$ precipitates. ${ }^{26}$

\section{Threshold Stress from Global n Calculation}

Having shown that there is an interaction between dislocations and $\gamma^{\prime}$ precipitates during creep deformation, the magnitude of a threshold stress remains to be determined. There are two approaches to determine the magnitude of the threshold stress that will be considered in this report. The first is convenient because it uses creep data that are already available and directly compares the behavior of Alloy 617 at different temperatures, however, analysis is complicated by the fact that the microstructure is evolving during the creep tests. Lagneborg and Bergman have shown that Eq. [5] may be rearranged into the following form: ${ }^{27}$

$$
\dot{\varepsilon}_{\min }^{1 / n}=A^{1 / n}\left(\sigma-\sigma_{0}\right)
$$

that groups the initial parameters into the coefficient, A, to allow for a direct determination of the threshold stress from the $\mathrm{x}$-intercept on a plot of the $\dot{\varepsilon}_{\min }{ }^{1 / n}$ versus $\sigma$. The Alloy 617 creep data are plotted in this manner for the four temperatures in Figure 16. Using a value of $n$ of 5.6 determined from the least squares fit to the data in Figure 10, this intercept method results in a threshold stress approximation of 65-70 MPa for Alloy 617 at $750{ }^{\circ} \mathrm{C}$. Although this method allows a threshold stress to be determined from conventional creep tests, it has the drawback that the size and spacing of the strengthening phase may be evolving during the relatively long duration of the test. An alternative, stress drop test method, to determine the threshold stress, described in the section below, may be completed in a relatively short time allowing for strict microstructure control to obtain a threshold stress value for a relatively constant precipitate microstructure during the test. ${ }^{28}$ 


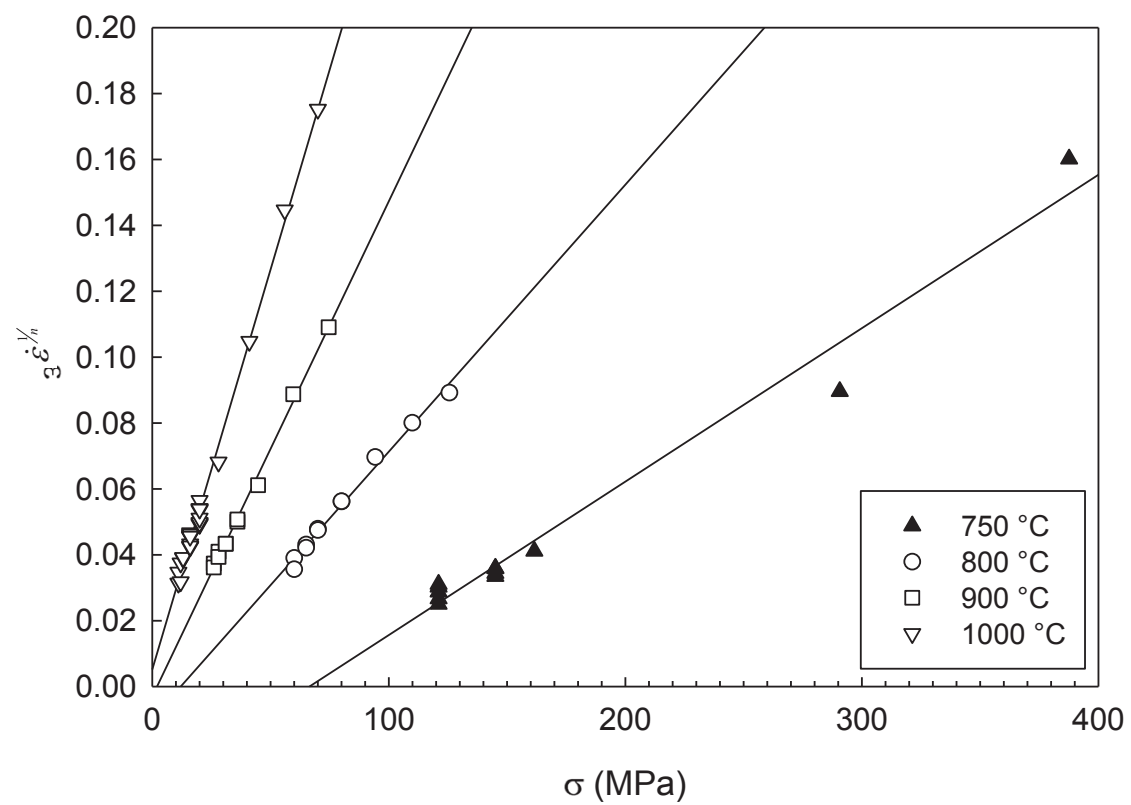

Figure 16. Lagneborg-Bergman plot showing the minimum creep rates raised to the $1 / n$-power for determination of the threshold stress with $n$ of 5.6.

\section{Stress Drop}

Stress drop tests were conducted, using a conventional lever arm creep frame configuration, to focus on the strain transients following small stress reductions and determine a threshold stress. ${ }^{21,22,29}$ An initial stress, $\sigma_{\mathrm{i}}$, was selected depending on the test temperature (200 MPa and $70 \mathrm{MPa}$ at 750 and $900^{\circ} \mathrm{C}$, respectively) to induce a constant positive creep rate, then, the stress was reduced by $\Delta \sigma$, as illustrated in Figure 17 . The stress drop results in an instantaneous strain contraction (AB), potentially followed by time dependent contraction (BC), depending on the magnitude of the stress reduction and/or temperature, and then a period of relatively constant strain (CD), until forward creep is again reestablished (D). The time period with neither negative nor positive creep, $\Delta \mathrm{t}$, was recorded after each stress reduction. Subsequent stress reductions were applied until the strain transients following a stress reduction could not be distinguished from the reestablishment of forward creep. The stress for the minimum achievable creep rate, $\sigma_{\mathrm{R}}$, is defined as:

$$
\sigma_{R}=\sigma_{i}-\sum \Delta \sigma
$$

where $\sigma_{R} \rightarrow \sigma_{0}$ as $\sum \Delta t \rightarrow \infty$, so a plot of $\sigma_{R}$ versus $\sum \Delta t$ allows for the quantitative determination of a threshold stress that is applicable regardless of the creep and/or recovery mechanisms occurring. Previous work has indicated that both strain resolution limitations and visual inspection of $\sigma_{R}$ versus $\sum \Delta t$ data can lead to significant error when extrapolating the threshold stress from the asymptote, therefore the $\sigma_{R}$ versus $\sum \Delta \mathrm{t}$ curve is fit using a stress-decrement model for recovery controlled creep, ${ }^{28}$ in which:

$$
\Sigma \Delta t=\frac{\mu^{2} b^{2}}{K}\left[\left(\sigma_{R}-\sigma_{0}\right)^{-2}-\left(\sigma_{i}-\sigma_{0}\right)^{-2}\right]
$$

where $K$ is a kinetic constant. 

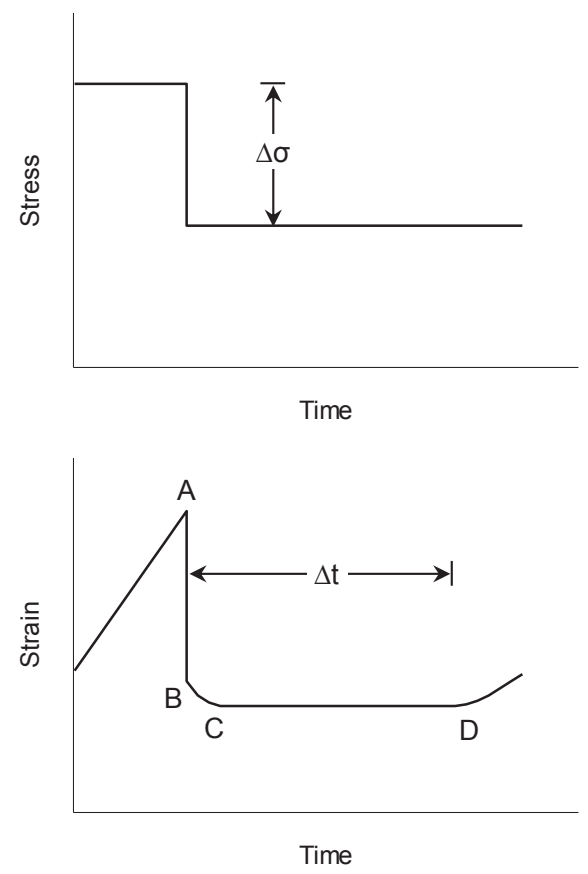

Figure 17. Schematic drawing showing the characteristic strain evolution following a stress reduction during a stress drop experiment.

Stress drop tests were conducted to determine a threshold stress value for Alloy 617 at $750{ }^{\circ} \mathrm{C}$ and $900{ }^{\circ} \mathrm{C}$. For the test conducted at $750{ }^{\circ} \mathrm{C}$, a creep specimen that had been previously aged at $750{ }^{\circ} \mathrm{C}$ for 650 hours was used in order to test an established intermediate average $\gamma^{\prime}$ radius of $30 \mathrm{~nm}$. The test time was limited to prevent more than a $10 \%$ increase in the size of the $\gamma^{\prime}$ precipitates during the test. A second stress drop test was completed at $900{ }^{\circ} \mathrm{C}$ on a creep specimen from the solution annealed plate that provided a starting microstructure with no $\gamma^{\prime}$ present to verify that the threshold stress was a consequence of dislocation motion being impeded by the $\gamma^{\prime}$ precipitates and not other factors such as secondary carbide precipitation and/or redistribution. At $900^{\circ} \mathrm{C}$, the $\gamma^{\prime}$ solvus is well exceeded thus there is no appreciable precipitation of $\gamma^{\prime}$ as previously confirmed by Wu et al. ${ }^{18}$ Shown in Figure 18 are the results from the stress drop tests completed at 750 and $900{ }^{\circ} \mathrm{C}$ fit to the Henderson and McLean model from Eq. Error! Reference source not found. ${ }^{28}$ The model results in threshold stress values of 77 and $3 \mathrm{MPa}$, respectively. The result at $750{ }^{\circ} \mathrm{C}$ is in reasonable agreement with the threshold stress value obtained from the Lagneborg-Bergman plot (Figure 16). At $900{ }^{\circ} \mathrm{C}$, the nearly zero value of saturation indicates the absence of a significant threshold stress. 


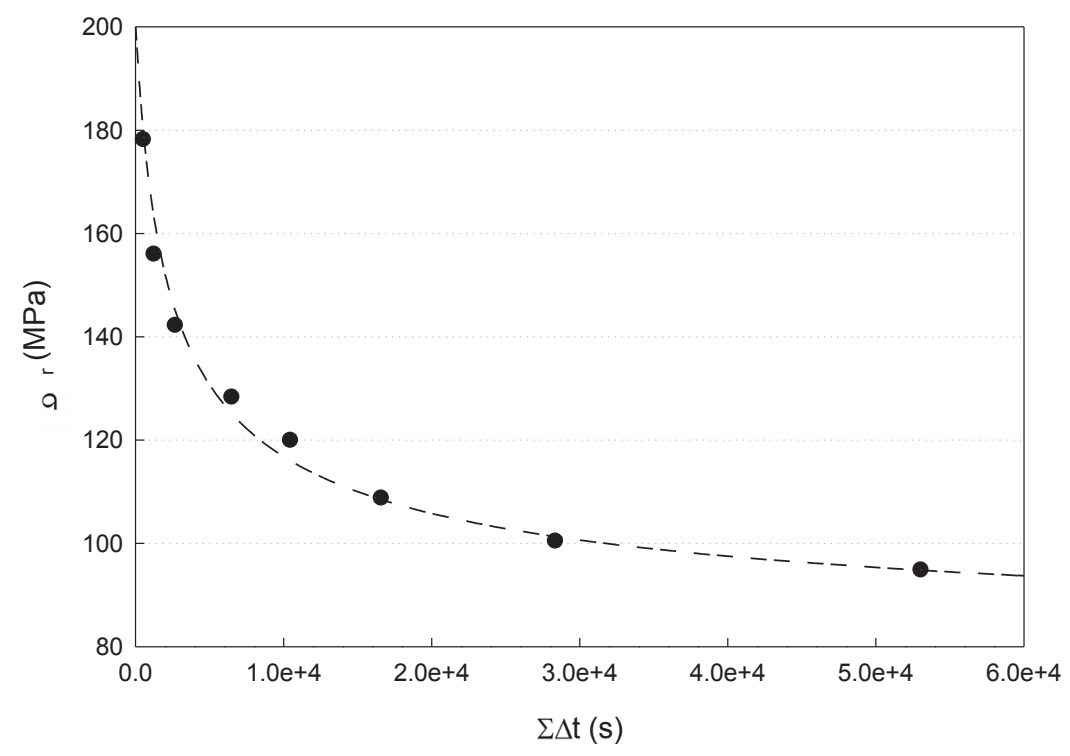

(a)

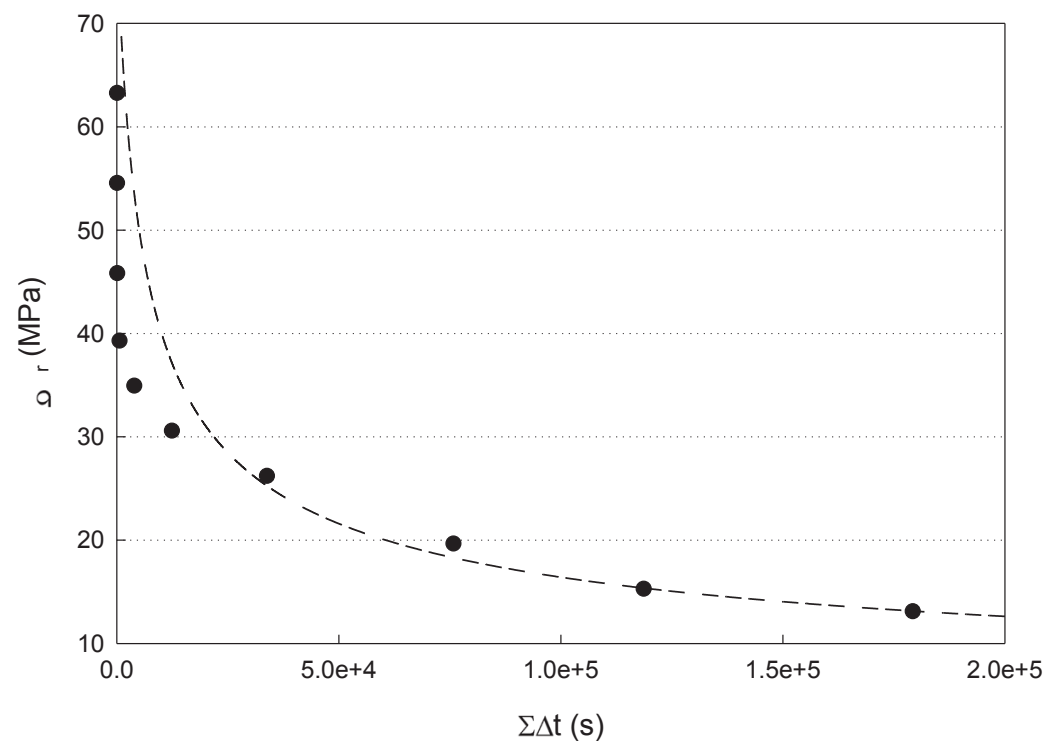

(b)

Figure 18. Plots of the stress drop tests at (a) $750{ }^{\circ} \mathrm{C}$ and (b) $900{ }^{\circ} \mathrm{C}$. The broken curves indicate the fit to the Henderson and McLean model and give threshold stress values of approx. 76.5 and 3.2 MPa for (a) and (b), respectively.

A stress exponent of around 5 for the higher temperature creep behavior indicates that Alloy 617 falls in the stress exponent range typical of class II alloys with a dislocation glide/climb creep mechanism active; ${ }^{10}$ this is in contrast to the apparent high stress exponent at $750{ }^{\circ} \mathrm{C}$. Incorporating the threshold stress determined from the stress drop experiment, the Zener-Hollomon approach is reconsidered with an apparent stress, $\sigma-\sigma_{0}$, in Figure 19 as opposed to consideration of only the applied stress in Figure 10. Correcting the 750 ${ }^{\circ} \mathrm{C}$ data with a threshold stress of $65 \mathrm{MPa}$ causes it to shift such that it resides on the same line as the 800 to $1000{ }^{\circ} \mathrm{C}$ data. Recalculating the value of the stress exponent in Eq. [4] by using the aforementioned threshold stress value for $750{ }^{\circ} \mathrm{C}$ results individually in a stress exponent, $\mathrm{n}$, of 5.4; a value consistent with 
the higher temperature data. Furthermore, the stress exponent determined for the entire temperature range remains unchanged at $n$ equal to 5.6 on the Zener-Hollaman plot with the corrected $750{ }^{\circ} \mathrm{C}$ data incorporated. As mentioned previously, an activation energy, $\mathrm{Q}_{\mathrm{c}}$, of $410 \mathrm{~kJ} / \mathrm{mol}$ fits the entire investigated Alloy 617 creep data. This value of $\mathrm{Q}_{\mathrm{c}}$ is higher than the value for self-diffusion in nickel, $284 \mathrm{~kJ} / \mathrm{mol}^{30}$ and molybdenum in nickel, $290 \mathrm{~kJ} / \mathrm{mol}^{31}{ }^{31}$ This activation energy for creep is consistent with previously published data for Alloy 617 reporting 320 to $500 \mathrm{~kJ} / \mathrm{mol}^{3}$

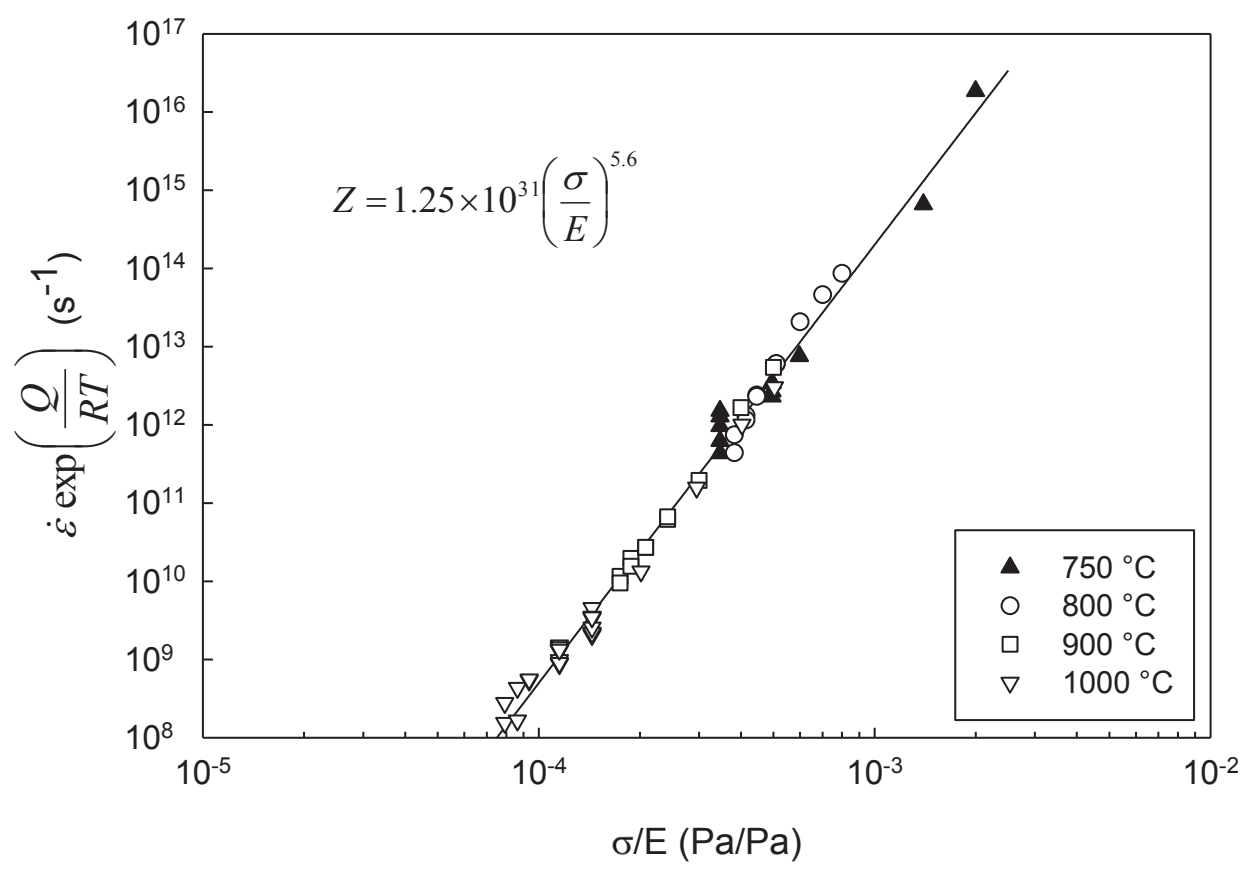

Figure 19. Zener-Holloman plot using a threshold stress of $65 \mathrm{MPa}$ on the $750{ }^{\circ} \mathrm{C}$ data. The resulting regression equation is also shown.

\section{Creep Stress Exponent, Activation Energy and Threshold Stress}

Because significant amounts of $\gamma^{\prime}$ precipitates are present only at $750{ }^{\circ} \mathrm{C}$, it is reasonable to assume that the $\gamma^{\prime}$ phase provides a barrier to dislocation motion that results in enhanced creep resistance via a threshold stress mechanism, similar to particle strengthening in $\mathrm{ODS}^{8,23}$ and Al-Mg-Sc alloys. ${ }^{26}$ The following discussion aims to mechanistically account for the unique creep behavior of Alloy 617 at intermediate temperatures by considering the evolving microstructure. The hypothesis suggested here, that the $\gamma^{\prime}$ precipitates alter the creep behavior, is consistent with the very limited presence of $\gamma^{\prime}$ at $800^{\circ} \mathrm{C}$ and full dissolution at $900{ }^{\circ} \mathrm{C}^{18}$, and also with the absence of a threshold stress in the $900{ }^{\circ} \mathrm{C}$ stress drop test. The amount of $\gamma^{\prime}$ particle growth during creep deformation varies for different test conditions; higher stress tests reach the minimum creep rate in shorter times and therefore have distributions of finer $\gamma^{\prime}$ precipitates than tests at lower stresses. Particle coarsening increases the interparticle spacing, resulting in a decrease in the shear stress for Orowan bowing and dislocation climb, and thus the apparent threshold stress. It should be noted that the threshold stress appears to be relatively constant across all of the $750{ }^{\circ} \mathrm{C}$ creep conditions investigated.

\section{Y' Precipitate Coherency}

To determine the mechanism of particle strengthening, it is necessary to understand in detail the nature of the precipitate-matrix interface (e.g., coherent or semi-coherent) and, if the interface is coherent, the magnitude of the misfit. Those issues will be discussed for $\gamma^{\prime}$ in Alloy 617 at $750^{\circ} \mathrm{C}$ in this section. Only a small lattice misfit exists between the $\gamma^{\prime}$ precipitates and surrounding $\gamma$ matrix in Alloy 617 based on the 
absence of interfacial misfit dislocations after extended times and the evolving $\gamma^{\prime}$ precipitate shape at 750 ${ }^{\circ} \mathrm{C}$. Previous work on Alloy 617 has reported that a computational thermodynamics analysis predicted lattice misfit at $760{ }^{\circ} \mathrm{C}$ is negative and of a magnitude of $0.1 .^{32} \mathrm{~A}$ misfit of that magnitude is consistent with some degree of coarsening, the evolving precipitate shape, ${ }^{33,34}$ and the fact that Mo partitions to the $\gamma$ phase. ${ }^{35}$ The relationship between the misfit and the precipitate shape has been studied in the Ni-Al-Mo system and as the magnitude of the lattice misfit increases, deviations from spherical to more cuboidal precipitates occur. ${ }^{33,34}$ The precipitate shape evolution is observed in Alloy 617 at relatively long aging times at $750{ }^{\circ} \mathrm{C}$, illustrated in Figure 11 (c), and indicates the presence of a coherency strain at the $\gamma-\gamma^{\prime}$ interface that is reduced through the establishment of preferred lower energy interfaces. The precipitates, however, remain predominately spherical during creep deformation through times beyond the time when the minimum creep rate occurs for the creep conditions investigated in this work. It is adequate to conclude that the precipitates are coherent in nature, based on the absence of interfacial misfit dislocations at long times, and that there is a small, negative misfit.

\section{Precipitate Bypass Mechanisms Model of Threshold Stress}

The minimum creep rate is determined by the balance of pinning dislocations by particles and mechanisms available for thermally activated bypass of the pinning points. Continued creep deformation requires mobile dislocations to bypass $\gamma^{\prime}$ precipitates by Orowan bowing, precipitate shearing, or climb. If the applied stresses are high enough, bowing or precipitate shearing will occur due to the faster kinetics of these processes; whereas at lower stresses dislocation climb dominates, as it is slower due to the significant amount of diffusion required, dominates. ${ }^{24,36}$ Addition of the threshold stress term into Eqn. [5] takes into consideration the stress necessary to activate the dominant particle bypass mechanisms. ${ }^{24}$ The relationship of the experimentally determined value $(65-70 \mathrm{MPa})$ to the stress required to activate the possible particle bypass mechanisms is tabulated in Table 5. The general lack of TEM evidence for $\gamma^{\prime}$ precipitate shearing in the post $750{ }^{\circ} \mathrm{C}$ creep specimens is sufficient to eliminate consideration of this bypass mechanism.

Calculations of strong pair precipitate shearing that follow the work of Kozar et al., ${ }^{37}$ on $\gamma^{\prime}$ precipitate strengthened nickel-base alloy, IN100, confirm the stresses required for particle shearing are much higher than the threshold stress at $750{ }^{\circ} \mathrm{C}$ and also higher than the applied creep stress (145 MPa for the $121 \mathrm{MPa}$ creep test and $155 \mathrm{MPa}$ for the $145 \mathrm{MPa}$ creep test). Detailed modeling of the shear stresses necessary for $\gamma^{\prime}$ precipitate bypass by Orowan bowing and climb are considered in the following paragraphs.

Table 5. Applied Stress versus Critical Stresses Required for Dislocation Bypass during Minimum Creep

\begin{tabular}{cccc}
\hline $\begin{array}{c}\text { Applied Stress } \\
(\mathrm{MPa})\end{array}$ & $\begin{array}{c}\text { Orowan Bowing } \\
(\mathrm{MPa})\end{array}$ & $\begin{array}{c}\gamma^{\prime} \text { Shearing } \\
(\mathrm{MPa})\end{array}$ & $\begin{array}{c}\text { Localized Climb - } \\
\text { Arzt (MPa) }\end{array}$ \\
\hline 121 & 140 & 145 & 55 \\
\hline 145 & 250 & 155 & 100 \\
\hline
\end{tabular}

\section{Orowan Bowing}

The shear stress, $\tau_{o}$, for Orowan bowing is

$$
\tau_{O}=\frac{\mu b}{L_{s}}
$$

where $\mu$ is approximately $60.5 \mathrm{GPa}$ for Alloy $617, b$ is the is estimated at $0.254 \mathrm{~nm}$, and $L_{s}$ is the edge to edge spacing between precipitates. The $\gamma^{\prime}$ particle radius in the statically aged material at the point of minimum creep rate (shown in Figure 8) is used since the particle size of aged material is representative of that in the crept material. Alloy 617 statically aged at $750{ }^{\circ} \mathrm{C}$ for $200 \mathrm{hrs}$, corresponding to the time to 
minimum creep in the $145 \mathrm{MPa}$ test, has an average precipitate radius of $17 \mathrm{~nm}$. In the case of the of the $121 \mathrm{MPa}$ test, minimum creep is reached after about $500 \mathrm{hrs}$ and thus the $\gamma^{\prime}$ precipitate radius is approximately $31 \mathrm{~nm}$. In both tests, the volume fraction of precipitates at minimum creep is approximately $2 \%$ (Table 3). A calculation of $L_{s}$ using the expression: $:^{37,38}$

$$
L_{s}=d \sqrt{\frac{8}{3 \pi f_{V}}}-d
$$

results in an interparticle spacing of $340 \mathrm{~nm}$ and $190 \mathrm{~nm}$ for the $121 \mathrm{MPa}$ and $145 \mathrm{MPa}$ creep conditions, respectively. Multiplying the shear stress by the Taylor factor for an FCC alloy, 3.1, to determine the applied stress to activate Orowan bowing of dislocations around the $\gamma^{\prime}$ precipitates results in values in the range of the applied stress of the creep test (Table 5): $140 \mathrm{MPa}$ for the $121 \mathrm{MPa}$ creep test and $250 \mathrm{MPa}$ for the $145 \mathrm{MPa}$ creep test. The ratio of the threshold stress to the Orowan bowing stress is quite high, 0.31 at $145 \mathrm{MPa}$ and 0.56 at $121 \mathrm{MPa}$.

Orowan bowing and precipitate shearing are kinetically favorable but require higher applied stresses than the experimentally determined threshold stress (representative of the dominating precipitate bypass mechanisms), as mentioned previously. Based on the above calculations, it is reasonable to expect some degree of precipitate bowing at $121 \mathrm{MPa}$, particularly as the particles continue to grow, and based on the fact that the Taylor factor provides an average number for a polycrystal. The very low volume fraction of $\gamma^{\prime}$ precipitates and large interparticle spacing relative to the particle diameter are indicative of an operative climb mechanism and thus the slower, diffusion-controlled climb mechanism is now considered.

\section{Diffusion-controlled Climb}

Dislocation climb around precipitates may occur by a local or general climb mechanism. Local climb involves the dislocation remaining in its glide plane in the matrix, thus forcing a sharp radius of curvature at the precipitate interface. A low threshold stress, magnitudes less than $1 \%$ of the Orowan stress at small precipitate volume fractions, and very low creep rates are typically associated with general climb. Neither of these is consistent with the creep behavior exhibited by Alloy 617 at $750{ }^{\circ} \mathrm{C}$. The high ratio of the threshold stress to the Orowan stress, determined above as 0.31 at $145 \mathrm{MPa}$ and 0.56 at $121 \mathrm{MPa}$, is much higher than that expected for general climb. Local climb of dislocations around particles has received much attention, particularly regarding incoherent precipitates in ODS alloys. Climb of dislocations around $\mathrm{Ni}_{3} \mathrm{Al}$ $\gamma^{\prime}$ precipitates in nickel-base superalloys has also been studied extensively but superalloys typically contain much higher volume fractions of $\gamma^{\prime}$, and thus have much smaller interparticle distances than the precipitates in Alloy 617. The local climb model developed by Rösler and Arzt is considered as is a modified model for general climb around coherent precipitates that predicts high threshold/bypass stresses. ${ }^{39,40}$

The non-interacting, dislocation-particle climb model for local climb is considered first. ${ }^{39}$ In order to account for the coherency of the $\gamma^{\prime}$ precipitates, the relaxation parameter, $\mathrm{k}$, is set equal to 1 . For alloys with a low volume fraction of precipitates, the shear stress necessary to increase the dislocation line length and bypass a precipitate by climb is

$$
\tau_{\text {climb }}=0.4 *(k)^{5 / 2} * \tau_{O}=0.4 * \tau_{O}
$$

resulting in approximately 56 and $100 \mathrm{MPa}$, for the $121 \mathrm{MP}$ and $145 \mathrm{MPa}$ creep conditions, respectively. The calculated value bounds the threshold stress in the stress drop experiment ( $78 \mathrm{MPa})$ and the threshold stress indicated by the $\dot{\varepsilon}^{1 / n}$ versus $\sigma$ plot of the experimental $750{ }^{\circ} \mathrm{C}$ creep data $(65-70 \mathrm{MPa})$ suggesting that dislocation bypass at these conditions may have a large component of the local climb process.

Despite the fact that the aforementioned model for local climb is consistent with the magnitude of the threshold stress in Alloy 617 at $750^{\circ} \mathrm{C}$, the difficulty of local climb around coherent precipitates requires 
the consideration of a recently developed model for general climb around coherent precipitates. ${ }^{39}$ This modification to the general climb model is able to account for the high threshold stresses observed by considering misfit forces that 'trap' the dislocation and prevent its release from the bypassed precipitate. The coherency of the precipitates and very low volume fraction of precipitates in Alloy 617 is similar to the Al-Sc alloy system, which contains a very low volume fraction of small (less than $10 \mathrm{~nm}$ ), coherent, ordered $\mathrm{L}_{2}$ precipitates in an FCC matrix. ${ }^{25,40}$ The misfit between the precipitate and matrix phase in Alloy 617 (estimated as $0.1 \%$ ) is an order of magnitude smaller than those investigated by Krug and Dunand ${ }^{40}$ ( 0.88 to $1.1 \%)$ and therefore would not be expected to trap dislocations following particle bypass to the degree necessary to account of the large ratio of threshold stress to the Orowan stress. This ratio is even greater in Alloy 617 than reported for the Al-Sc alloys.

\section{Dominant Creep Mechanism}

The stresses estimated using fundamental models of the dislocation bypass mechanisms correlate well with the TEM observations of the creep deformed microstructures. At the point of minimum creep rate, the modeling suggests that creep deformation at $750{ }^{\circ} \mathrm{C}$ and $121 \mathrm{MPa}$ condition occurs by either Orowan bowing or a climb mechanism. The calculated stress required for Orowan bowing (140 MPa) is just above the applied stress but is determined using the Taylor factor, which provides an estimate for a polycrystal. TEM analysis did show evidence of looped $\gamma$ ' precipitates; however, only a fraction of the precipitates were looped and only a single loop was present at a given precipitate. Dislocations are also observed in configurations that indicate climb is occurring as well. The modeling suggests that climb occurs by a local climb mechanism, however, it cannot be purely local climb as it is energetically unfavorable for coherent precipitates. A sharp radius of curvature of the dislocation at the precipitate-matrix interface is not observed in weak beam images of climb dislocations ( $1^{\text {st }}$ row, $2^{\text {nd }}$ column of Figure 15$)$, as would be expected during purely local climb.

Considering the calculated stresses for bypass combined with the TEM evidence of particle bypass and the low threshold stress relative to that necessary for Orowan bowing or precipitate shearing, the dominating mechanism at the point of minimum creep is the climb of dislocations around the $\gamma^{\prime}$ precipitates. At the 121 MPa condition, by minimum creep or soon after there is also some degree of Orowan bowing, not unexpected based on the estimates of the bypass stress. Figure 15 illustrates how the stress at which various bypass mechanisms become active evolve as creep deformation progresses due to the influence of the coarsening precipitates. The precipitation models illustrated in Figure 15 agree well with the observed bypass mechanisms in the interrupted TEM images. For example, at $2 \%$ creep strain and $121 \mathrm{MPa}$, the precipitates have had additional time to coarsen beyond their size at minimum creep allowing the Orowan bowing mechanism to become more favorable. At the higher stress of $145 \mathrm{MPa}$, the precipitates are finer, having experienced less coarsening so the stress required for Orowan bowing is much higher and therefore greater than the applied creep stress. This is consistent with the absence of any evidence of Orowan bowing in the TEM of crept specimens; resulting in precipitate bypass occurring solely by climb mechanisms.

\section{EXPERIMENTAL RESULTS ON CREEP OF TUBES}

As noted above, creep tests were carried out on tubes machined from Alloy 617 plate using internal gas pressure to apply the stress. A fixed test period under temperature and pressure was applied after which the diameter of the tube was measured. Typical results are shown in Figure 20; note that the increase in

diameter shown in the figure is corrected for oxide gorwth using the change in diameter of the undeforming end cap as the standard. As indicated by the finite element model used to develop the test configuration, the strain is at a maximum in the center of the test section and is relatively uniform until failure is approached. 


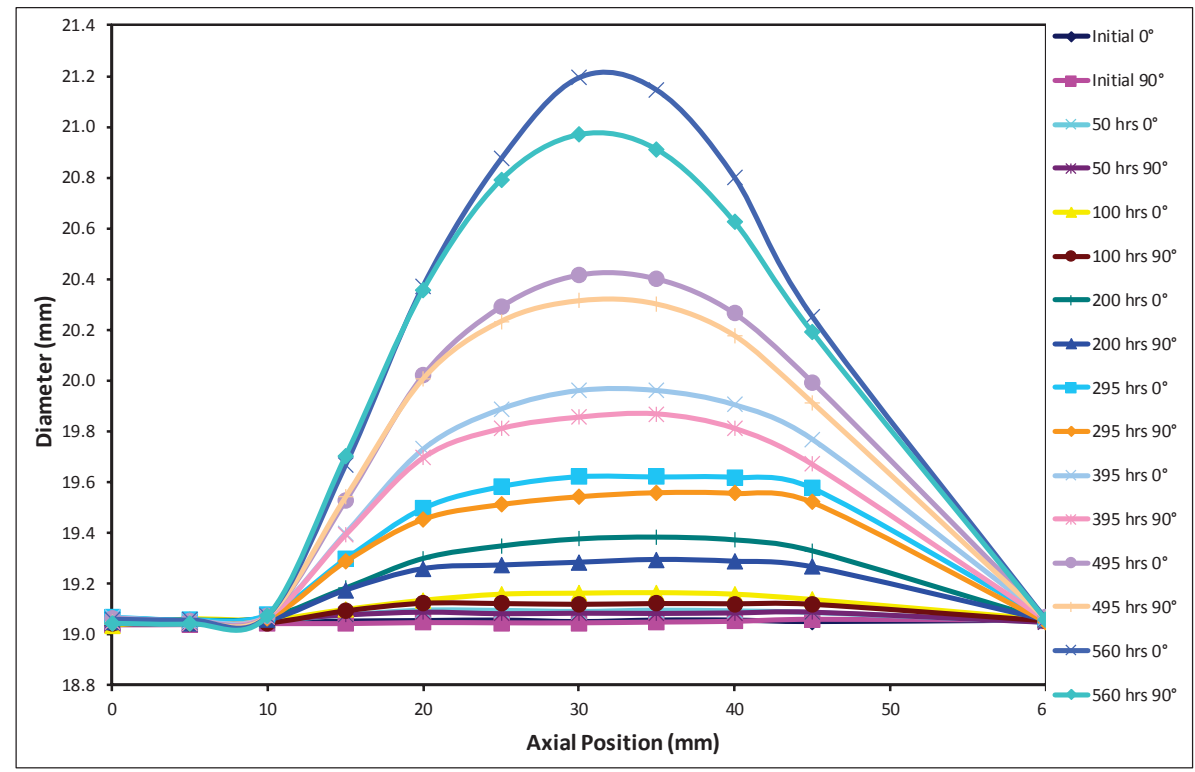

Figure 20. Tube diameter as a function of axial position and time of exposure.

The stresses in the tube specimens were calculated and are presented in Table 6. The first BSU specimen used the same conditions and specimen geometry as the first INL specimen for repeatability. The second INL specimen had a larger diameter and thickness but was run with a pressure designed to give the same maximum hoop stress as the first; however, the maximum effective stress turns out to be slightly higher.

Table 6. Test pressure, dimensions and calculated stresses for pressurized tube creep specimens.

\begin{tabular}{|c|c|c|c|c|c|c|c|c|}
\hline & \multirow{2}{*}{$\begin{array}{c}\mathrm{P} \\
\mathrm{MPa} \\
\text { (psi) } \\
\end{array}$} & \multirow{2}{*}{$\begin{array}{l}\text { OD } \\
\mathrm{mm} \\
\text { (in) }\end{array}$} & \multirow{2}{*}{$\begin{array}{c}\text { thick } \\
\mathrm{mm} \\
\text { (in) }\end{array}$} & \multirow[b]{2}{*}{ location } & \multicolumn{4}{|c|}{ stress (MPa) } \\
\hline & & & & & radial & axial & hoop & effective \\
\hline \multirow[t]{2}{*}{ INL 1} & $\begin{array}{c}3.4 \\
(500)\end{array}$ & $\begin{array}{l}12.7 \\
(0.5)\end{array}$ & $\begin{array}{c}0.89 \\
(0.035)\end{array}$ & OD & 0 & 9.79 & 19.58 & 16.96 \\
\hline & & & & ID & -3.45 & 9.79 & 23.03 & 22.93 \\
\hline \multirow[t]{2}{*}{ INL 2} & $\begin{array}{c}5.3 \\
(773)\end{array}$ & $\begin{array}{c}19.0 \\
(0.75)\end{array}$ & $\begin{array}{c}2.0 \\
(0.078)\end{array}$ & OD & 0 & 8.86 & 17.71 & 15.34 \\
\hline & & & & ID & -5.33 & 8.86 & 23.04 & 24.57 \\
\hline \multirow[t]{2}{*}{ INL 3} & $\begin{array}{c}4.4 \\
(635)\end{array}$ & $\begin{array}{c}19.0 \\
(0.75)\end{array}$ & $\begin{array}{c}2.0 \\
(0.078)\end{array}$ & OD & 0 & 7.28 & 14.55 & 12.60 \\
\hline & & & & ID & -4.38 & 7.28 & 18.93 & 20.19 \\
\hline \multirow[t]{2}{*}{ BSU 1} & $\begin{array}{c}3.4 \\
(500)\end{array}$ & $\begin{array}{l}12.7 \\
(0.5)\end{array}$ & $\begin{array}{c}0.89 \\
(0.035)\end{array}$ & OD & 0 & 9.79 & 19.58 & 16.96 \\
\hline & & & & ID & -3.45 & 9.79 & 23.03 & 22.93 \\
\hline \multirow[t]{2}{*}{ BSU 2} & $\begin{array}{c}3.4 \\
(500)\end{array}$ & $\begin{array}{c}19.0 \\
(0.75)\end{array}$ & $\begin{array}{c}1.0 \\
(0.039)\end{array}$ & OD & 0 & 14.04 & 28.07 & 24.31 \\
\hline & & & & ID & -3.45 & 14.04 & 31.52 & 30.28 \\
\hline \multirow[t]{2}{*}{ BSU 3} & $\begin{array}{c}2.9 \\
(425)\end{array}$ & $\begin{array}{c}19.0 \\
(0.75)\end{array}$ & $\begin{array}{c}1.0 \\
(0.039)\end{array}$ & OD & 0 & 11.93 & 23.86 & 20.67 \\
\hline & & & & ID & -2.93 & 11.93 & 26.79 & 25.74 \\
\hline
\end{tabular}


Radial creep strain is shown in Figure 21 as a function of the test time for several stresses at $950^{\circ} \mathrm{C}$. It can be seen that the creep deformation shows little or no primary creep and the minimum creep rate occurs very early in the test. As expected the time to rupture decreases rapidly as the effective stress is increased. The strain to failure is generally higher as the effective stress is decreased. It should be noted that specimen thickness was increased from 1 to $2 \mathrm{~mm}$ for some of the tests. Early test results suggested enhanced creep cavity formation in the tubes compared to uniaxial specimens and that grain boundary oxidation associated with the surface of the tube was a nucleation site for cracks. Increasing the specimen thickness was designed to investigate the influence of the large surface area of the tube with the environment on the observed behavior.

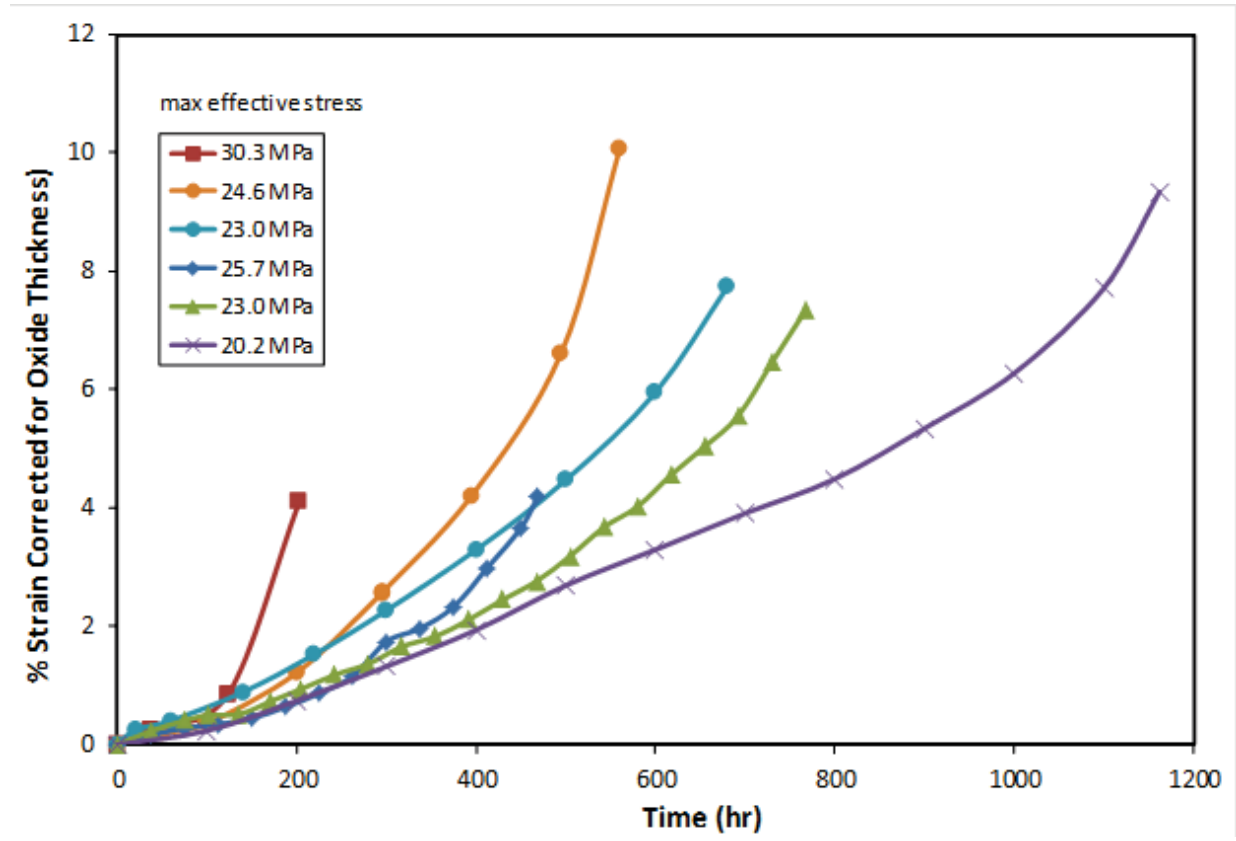

Figure 21. Radial creep strain as a function of test time for pressurized tube experiments.

A conventional uniaxial creep curve, tested past the strain to achieve minimum creep rate, is shown in Figure 22 with several pressurized tube creep curves under similar conditions. It can be seen in Figures 22 and 23 that in general there is very little primary or secondary creep in the pressurized tubes. The majority of creep strain occurs in a regime where the creep rate increases with increasing time (or strain). The creep rate is approximately comparable between the uniaxial specimen and the pressurized tubes for the early part of the test; however, the rate of strain in the tube eventually becomes significantly larger in the tubes. Time to rupture is less than for uniaxial creep, as reported previously. ${ }^{5,41}$

A photo of a tube that was tested to a failure strain of about $8 \%$ is shown in Figure 23. The fracture that resulted in gas leakage is shown in a low magnification macrograph in Figure 24. The failure in this tube is macroscopically similar to all of the fractures observed in failed tubes. In every case the fracture was several millimeters in length and parallel to the long axis of the tube. This crack orientation is perpendicular the maximum principal stress/strain (hoop), as expected. A previous study on Alloy $800 \mathrm{H}$ also reported this crack orientation for tubes where hoop stress was dominant. ${ }^{5}$ 


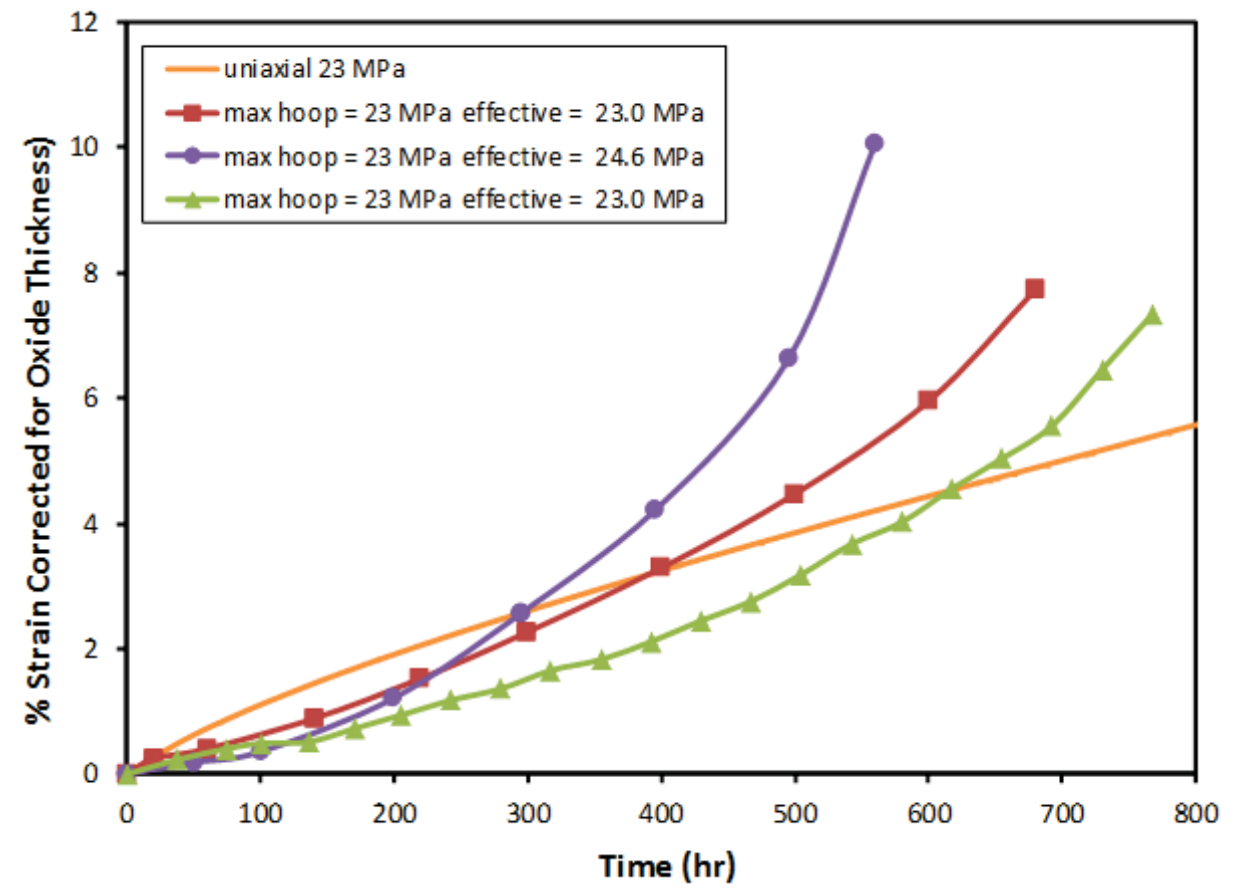

Figure 22. Comparison of creep curves from several pressurized tubes to a conventional uniaxial creep test under similar stress.

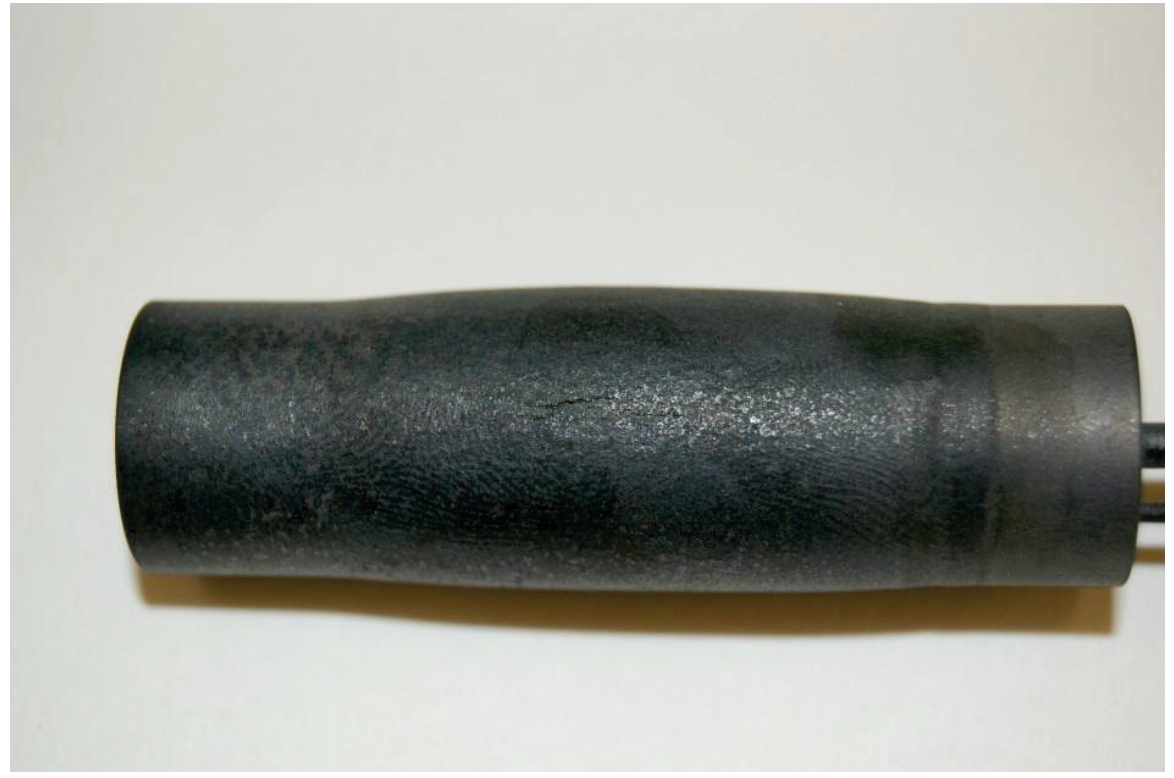

Figure 23. Photograph of a tube that was tested to a failure strain of about $8 \%$. 


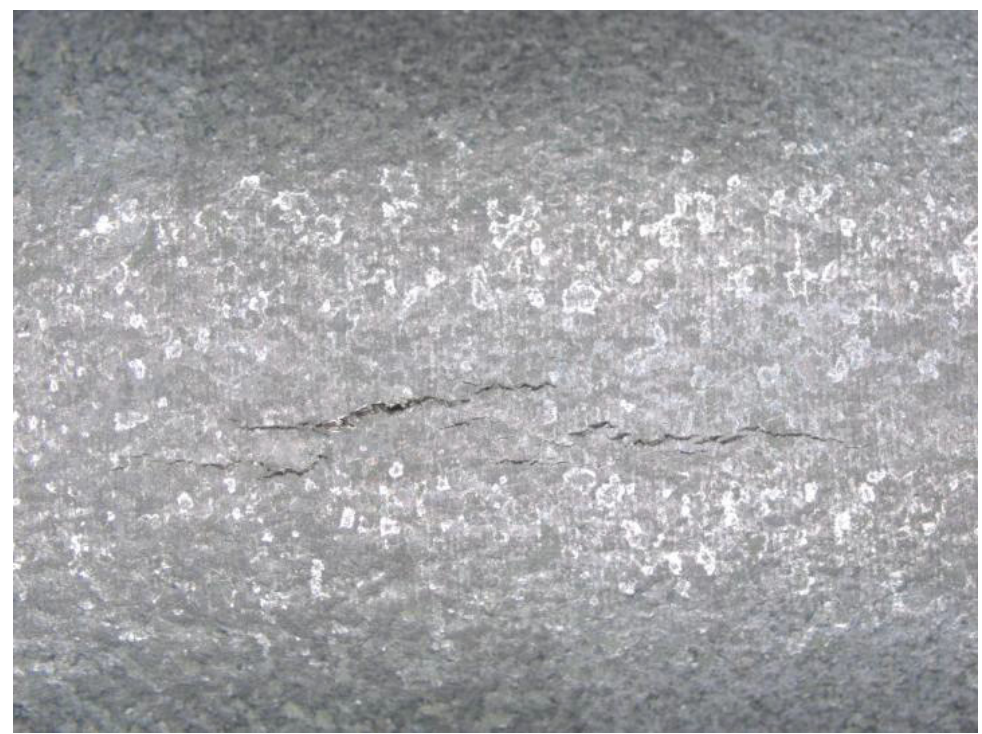

Figure 24. Macrograph showing tube fracture that resulted in gas leakage.

Because there is a strain gradient along the length of the tube (Figure 20), it was possible to examine the microscopic creep damage as a function of strain by sectioning along the length of a failed tube away from the fracture. Cross-sections of the tube crept at $23 \mathrm{MPa}$ are shown in Figure 25 (a) and (b) from regions that experienced radial strains of approximately 6 and $8 \%$, respectively. It can be seen that there is some internal damage through the thickness of the tube, however, the longest cracks appear to nucleate at the outer surface. Note that because the tube was pressurized using high purity argon gas there is less oxidation at the inner surface, compared to the outer surface that was exposed to air.

Figure 26 shows an etched cross-section through a tube that experienced approximately $10 \%$ strain; the image was taken in a region away from the final fracture. This figure shows that continued development of internal damage occurs on an angle of approximately $45^{\circ}$ to the tube diameter. It can also be seen that the majority of cracking and internal damage occurs along grain boundaries. A fracture that traverses the entire specimen is shown in Figure 27. It can be seen that the fracture is on an angle of about $45^{\circ}$ to the radial axis and occurs by an intergranular mechanism. The $45^{\circ}$ slanted fracture is typical of the shear failure mode expected for the biaxial stress state of the center span of the tube. 


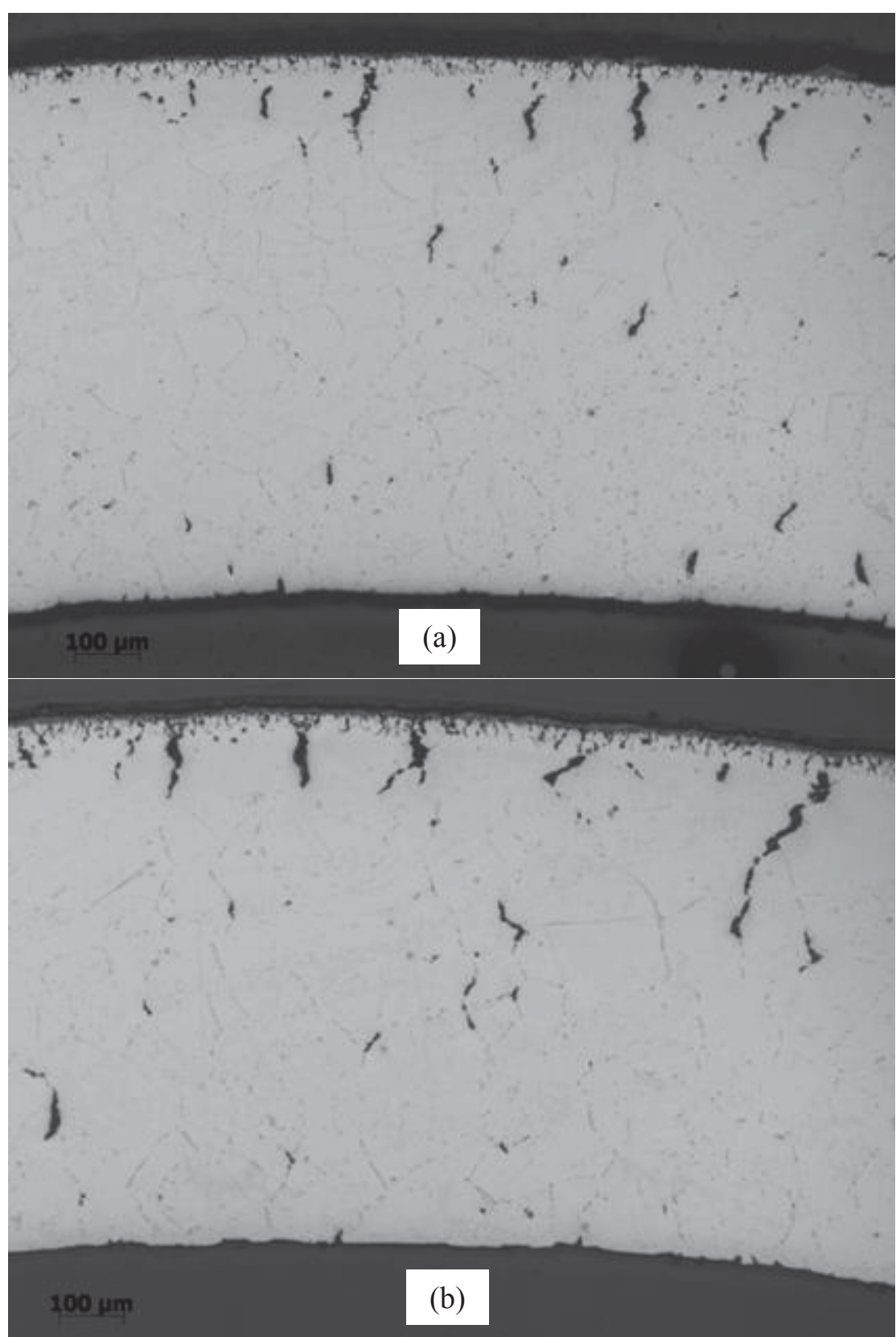

Figure 25. Cross-sections of the tube crept at $23 \mathrm{MPa}$ from regions that experienced (a) $6 \%$ and (b) $8 \%$ strain. 


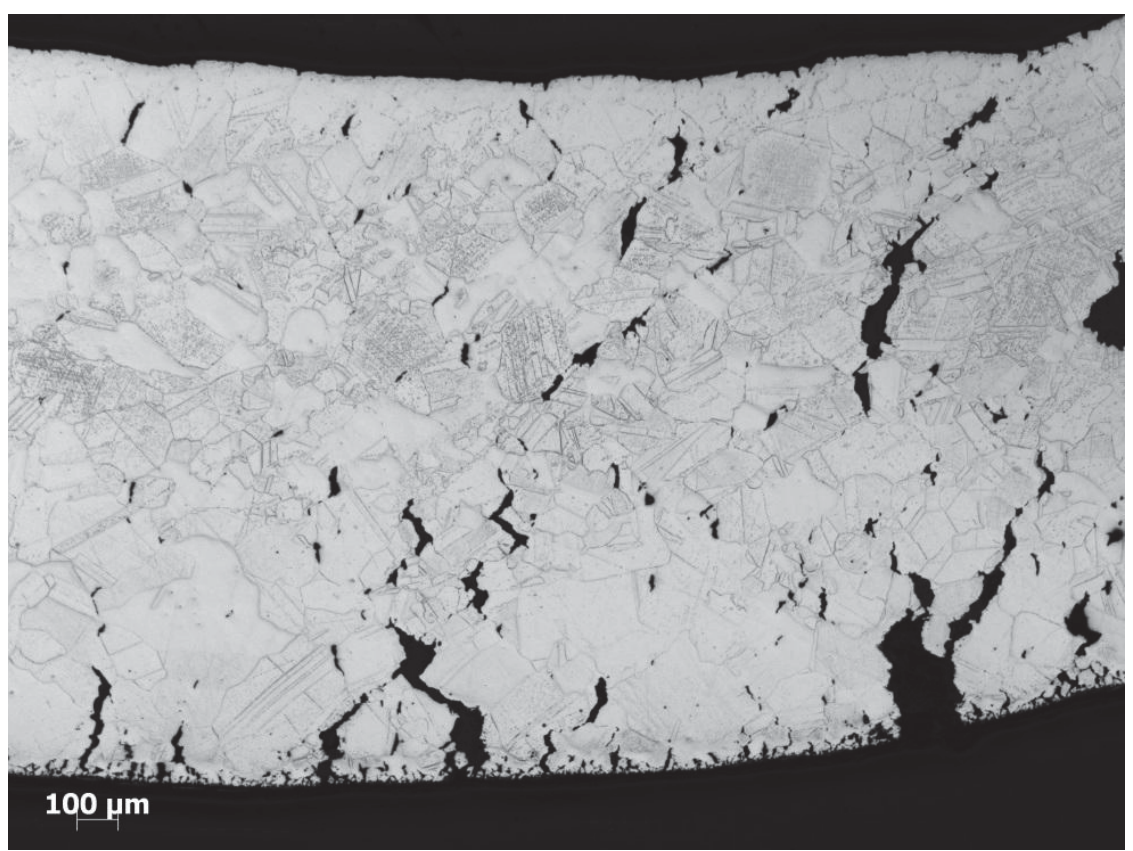

Figure 26. Etched cross-section through a tube that experienced approximately $10 \%$ strain.

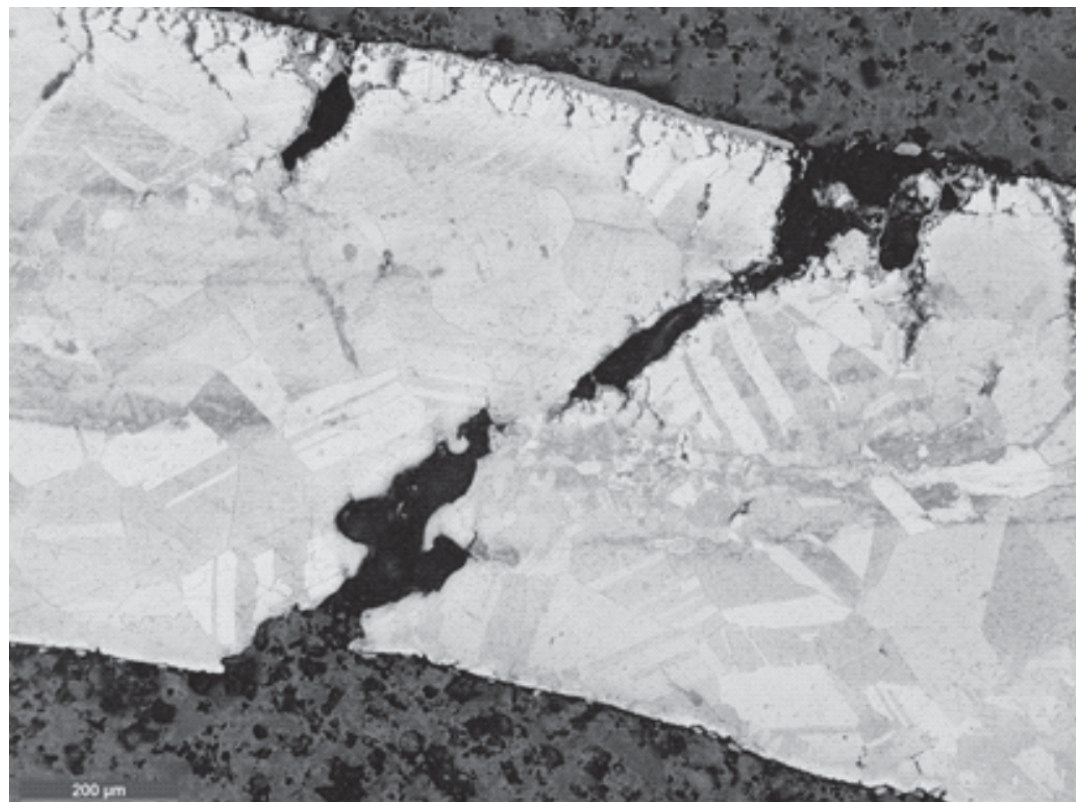

Figure 27. A fracture that traverses the entire thickness of the tube wall.

\section{DISCUSSION}

The creep behavior of pressurized tubes differs in several significant ways compared to that determined using conventional uniaxial creep tests. It was shown in Figure 22 that there is little or no primary creep in the tubes. The appearance of increasing creep rate with increasing creep time (or strain) is commonly associated with formation of cavitation in austenitic stainless steels. The current VHTR and SMR research program that is characterizing Alloy 617 has extensively studied cavitation during creep and demonstrated that for this alloy there can be significant tertiary creep before cavitation occurs. Results for porosity 
formation as a function of the tertiary creep strain during uniaxial creep testing at two temperatures are shown in Figure 28. The data presented in Figure 28 are averages for three hundred images from the gage section of specimens where the creep test was interrupted at varying total strain.

Comparing the image shown in Figure 26 for a tube strained to approximately $10 \%$ to the curves shown in Figure 28 it can be seen qualitatively that there is significantly greater porosity in the pressurized tube. Quantitative measurement of the porosity in the tubes crept to 6 and $8 \%$ strain showed total porosity of approximately 0.4 and $2 \%$, respectively. It was shown in Figure 21 that the strain in pressurized tubes was essentially in the tertiary creep regime for the entire experiment.

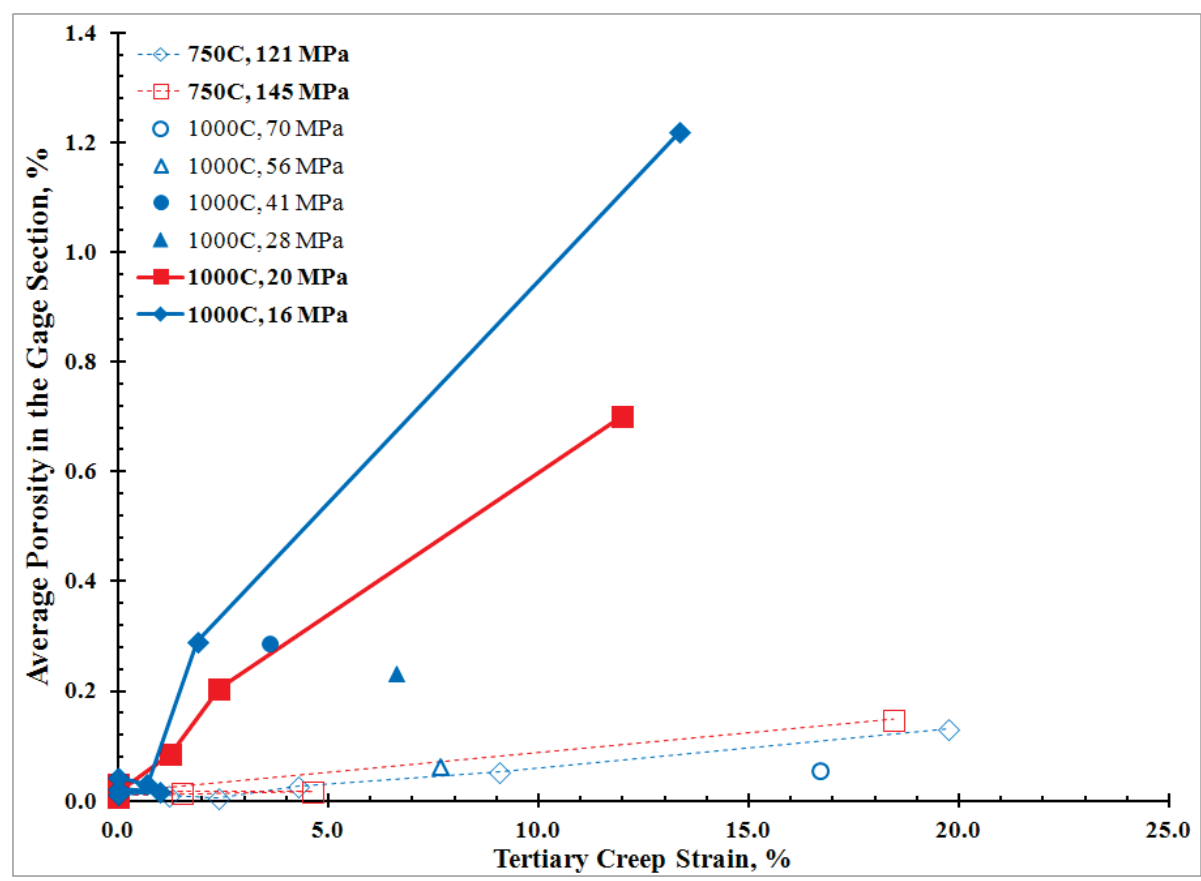

Figure 28. Average porosity in the gage section from interrupted conventional uniaxial creep tests as a function of the strain in tertiary creep.

In order to examine the potential for extrapolating the experimental results shown in Figure 28 for creep porosity in the tertiary creep regime to a more broad set of temperatures a normalization scheme using the applied creep stress divided by the temperature corrected elastic modulus was developed. The measured average porosity in the gage section as a function of the normalized stress is shown in Figure 29. For the pressurized tube creep tests reported here the normalized stress is approximately 0.0002 . For that value, the curve shown in Figure 29 suggests that the anticipated porosity in a uniaxial test would be approximately $0.4 \%$ for a total creep strain of $20 \%$. It can be seen from the micrographs of pressurized tubes after even $10 \%$ creep strain that the porosity is on the order of 4 to $10 \%$ depending on the location in the tube. 


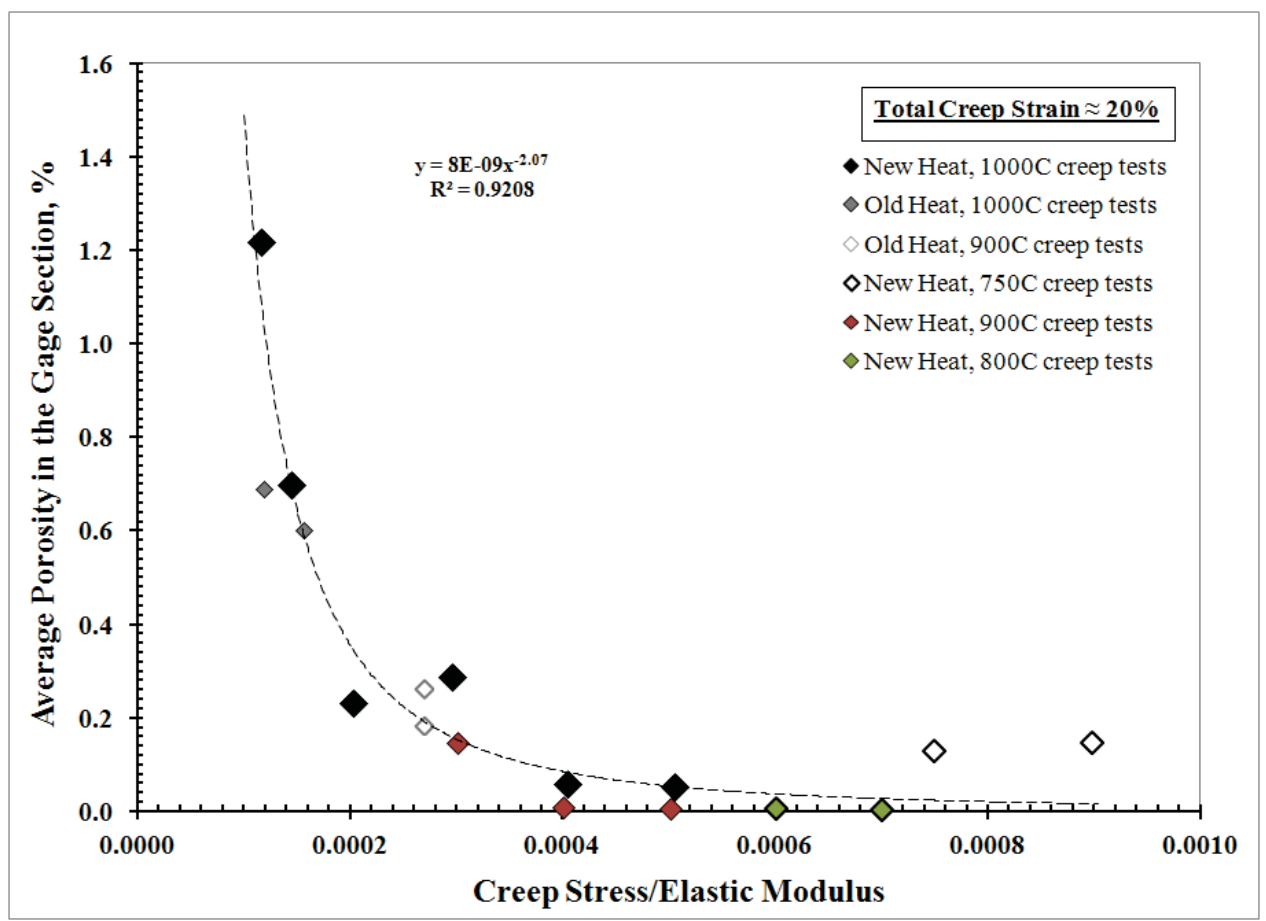

Figure 29. Average porosity in the gage section of interrupted conventional creep specimens as a function of the normalized creep stress.

These results are in qualitative agreement with results for thin walled hot drawn tubes examined at University of Illinois under a Nuclear Energy University Program (NEUP) project. ${ }^{41}$ Those experiments also indicated more rapid failure and greater formation of porosity in pressurized tubes compared to uniaxial creep tests. It should be noted that one of the motivations of the current work was to directly compare the same material for both types of creep testing by machining tubes from plate, since the NEUP project used material that had grain size differences and inhomogeneity result from the hot working to achieve thin wall tube.

The strain or time to failure might also be expected to differ between pressurized tubes and uniaxial tests because of the method of applying the stress. In the case of pressurized tubes failure is defined at the loss of ability to contain gas pressure. The fraction of voids that is thought to result in interconnected porosity is conventionally taken to be on the order of 5\%. Formation of a local pore fraction of this magnitude will then terminate the test. In a conventional round bar uniaxial creep test the ability to maintain a load is the failure criterion. Although the creep rate increases as the cross sectional area is reduced by pore formation, it is likely that higher than $5 \%$ void fraction can exist in a specimen that is still nominally able to support a load.

Optical microscopy on tubes crept to different total strains also showed that the number and spacing of cracks originating from the surface was established by the time a specimen had experienced $6 \%$ strain, shown in Figure 25 (a). Further strain increased the depth of penetration of these cracks and the width of the opening at the surface, Figures 25 (b) and 26. Previous work in this program suggests that the origin of cracks from the exterior surface is likely the aluminum oxides that forms on grain boundaries and penetrates into the material along grain boundaries. It is difficult to confirm that mechanism here since there is a region that is depleted of carbides near the surface due to oxidation (carbides decorate the grain boundaries in the specimen interior). The crack spacing is on the order of $200 \mu \mathrm{m}$ which is slightly greater than the average grain size of $154 \mu \mathrm{m}$, suggesting that many, if not all, of the grain boundaries that intersect the surface form cracks. In Figure 30 carbides that are below the denuded zone, that appear to delineate grain boundaries that connect to surface cracks. 


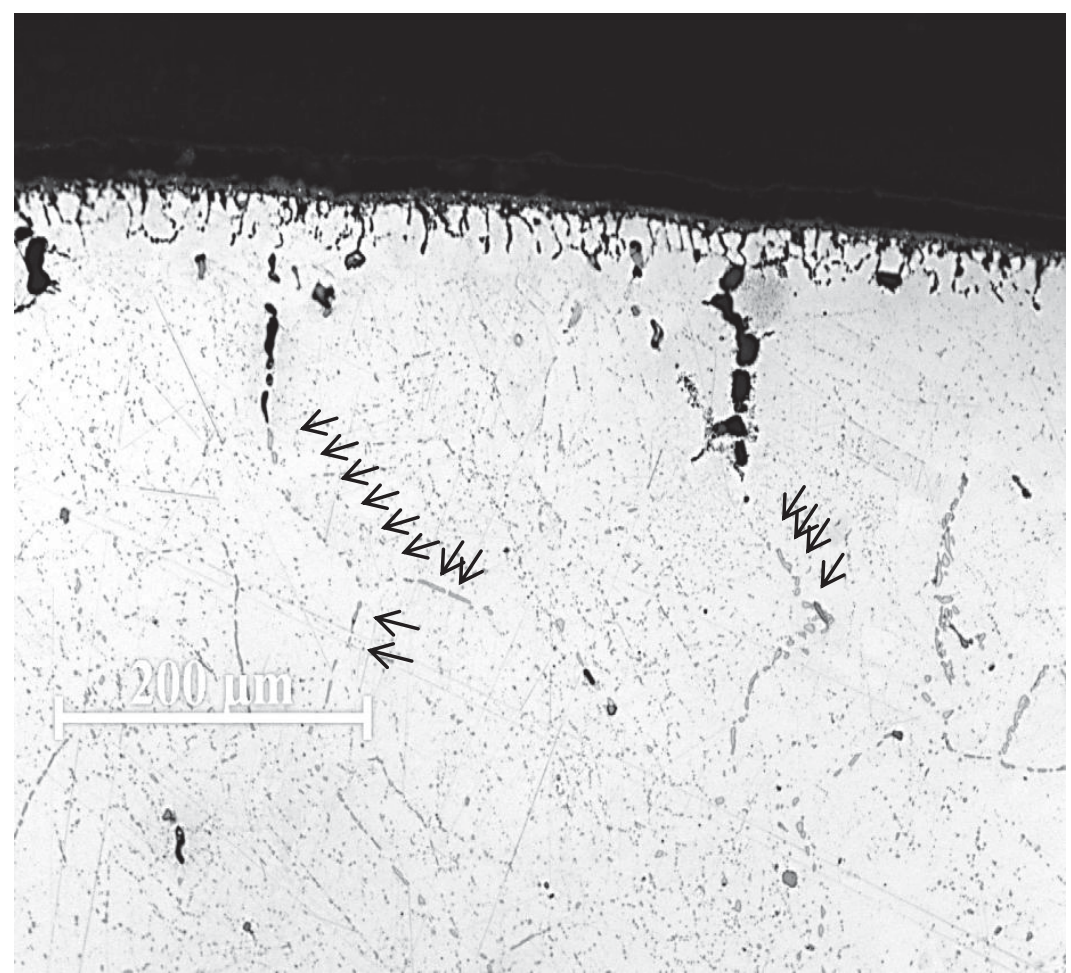

Figure 30. Etched microstructure showing carbides along the grain boundaries in the area below the denuded zone near the surface that occurs as a result of oxidation.

It thus appears that the localization of damage that results in premature failure (compared to the uniaxial case) results from the initial formation of surface cracks, a limited number of which propagate through the specimen as a result of redistribution of stresses ahead of the crack tip (Figures 26 and 27). This stress localization and redistribution has been extensively studied at the continuum level and is consistent with experimental results for Alloy $800 \mathrm{H}$. Localization of the creep damage in tubes is in contrast to the relatively homogeneous distribution of pores and voids that is observed in uniaxial specimens even up to $20 \%$ tertiary creep strain. ${ }^{42,43,5}$

One way to normalize the effect of temperature and stress on the time to rupture is to construct a LarsonMiller plot. Figure 31 shows the experimentally determined Larson-Miller data for pressurized tubes along with a comparable set of conventional creep data for the same Alloy 617 plate. Although it is difficult to separate a difference between material behavior and the definition of failure, it can be seen that the pressurized tube data generally fall below the data for conventional tests. It may be that since the log of the failure time is used in the analysis that any difference between tubes and uniaxial tests in minimized in the plot. 


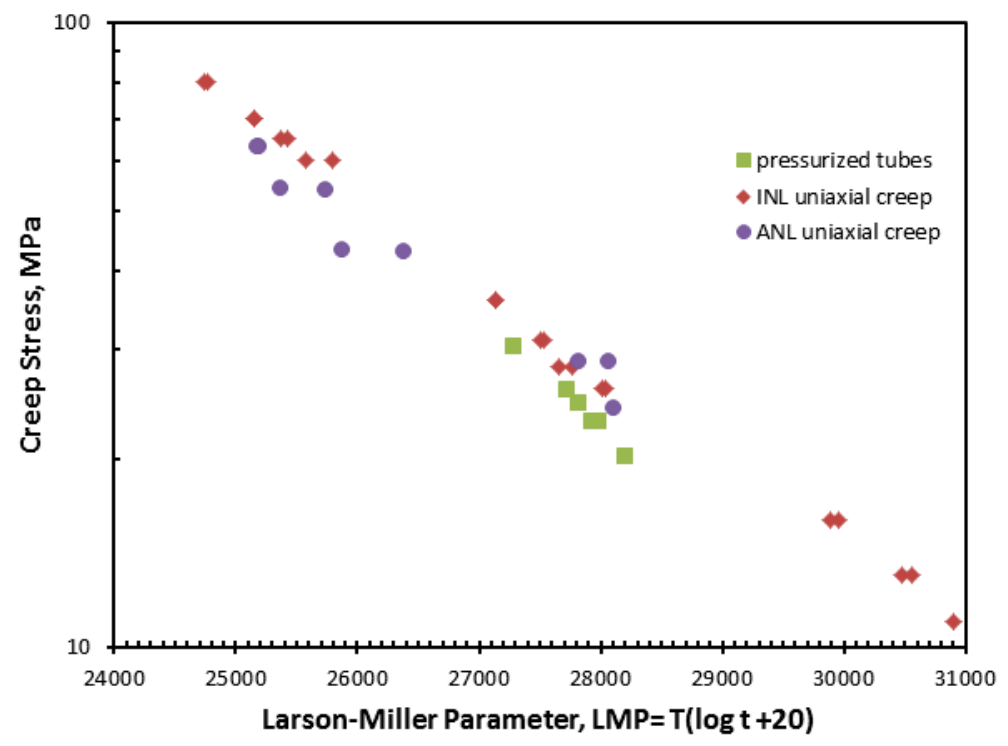

Figure 31. Larson-Miller plot for time to rupture of uniaxial specimens and pressurized tubes.

In addition to the time to rupture, a relationship between the minimum creep rate and the time to failure, known as the Monkman-Grant relationship, has been developed and is used in engineering design. Monkman-Grant curves have been developed for Alloy 617 for conventional uniaxial tests on the plate described in this report and recently published for another heat of the alloy. ${ }^{2}$ From this relationship the Monkman-Grant ductility parameter can be determined. ${ }^{44}$ A plot of the time to rupture as a function of the minimum creep rate is shown in Figure 32 for conventional and pressurized tube creep tests. It can be seen from the figure that for a given strain rate the time to rupture for the pressurized tube is significantly less than for the comparable uniaxial test. There is a suggestion from the experimental results that there is a systematic difference between the experimental data from INL and BSU, although more testing is planned to confirm this. It should be noted that the majority of testing done at INL was on $2 \mathrm{~mm}$ thick tubes, while all of the BSU tests were done on the $1 \mathrm{~mm}$ thick tubes.

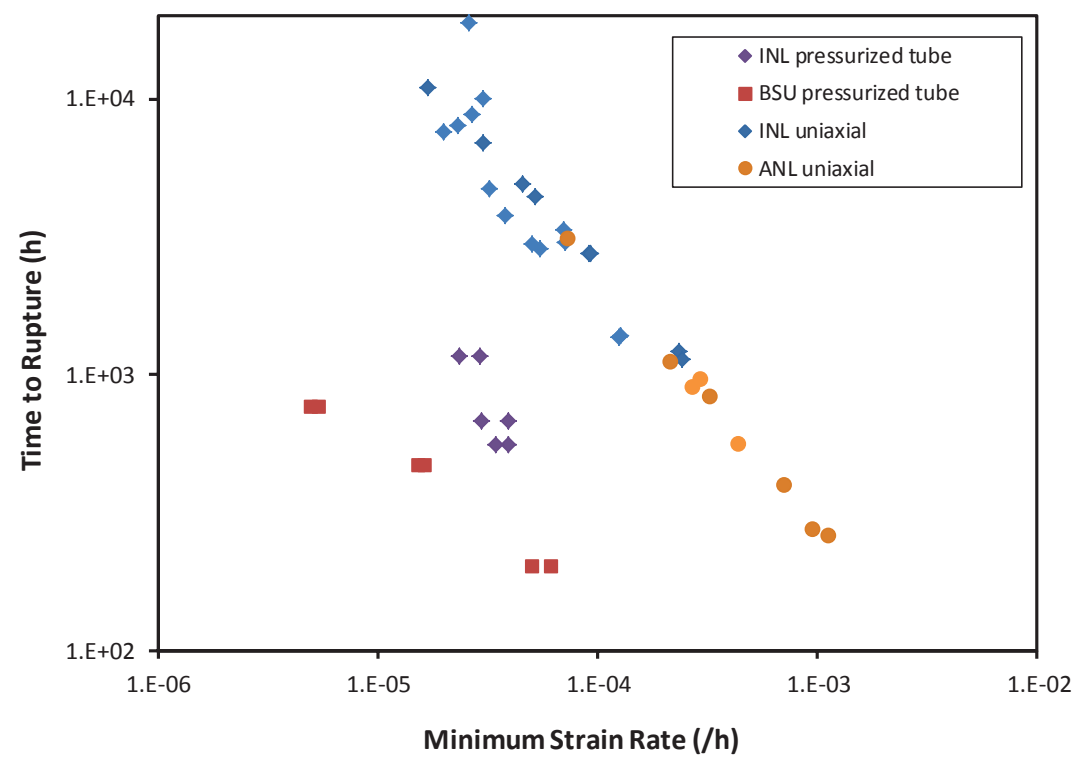

Figure 32. Monkman-Grant plot of time to rupture as a function of minimum creep rate for uniaxial specimens and pressurized tubes. 


\section{CONCLUSIONS}

An experimental method has been developed to successfully measure the creep of Alloy 617 using cylinders with internal pressurization. Tubes subjected to creep in this manner exhibit less primary and secondary creep compared to conventional uniaxial tests.

In the process of developing a constitutive model for the minimum creep rate it was demonstrated that while a simple Norton law described behavior above $750^{\circ} \mathrm{C}$, a threshold stress model was necessary to converge the $750^{\circ} \mathrm{C}$ minimum creep rate onto the same Zener-Hollaman plot. The magnitude of the threshold stress was found to be 75MPa. By applying the threshold stress model for the lower temperature, a power law exponent of 5 was obtained and the activation energy was found to be $410 \mathrm{~kJ} / \mathrm{mol}$.

Comparison of strengthening models with detailed TEM analysis of dislocation-particle interaction in crept specimens indicates that strengthening is a result of local dislocation climb and Orowan bowing, depending of exactly the creep time and stress.

Failure of the pressurized tubes initiates at low strain by cracking of the majority of grain boundaries that intersect the exterior surface. For radial strains of about $5 \%$, the total creep damage fraction is equivalent to uniaxial test specimens with similar tertiary creep strain. Above this value the surface nucleated cracks begin to open rapidly with increasing strain and the volume fraction of creep damage exceeds that for comparable uniaxial tests. Final failure, defined for the pressurized tubes as loss of the ability to maintain pressure, occurs by linking of damage ahead of one of the cracks that nucleate on the surface on a $45^{\circ}$ angle to the tube radius.

It appears that the results of pressurized tube test describe a different Monkman-Grant relationship compared to uniaxial data. Time to rupture is also somewhat reduced when the comparison is made using a Larson-Miller plot for both pressurized tubes and uniaxial tests.

\section{REFERENCES}

1. Corum, J. M. and J. J. Blass, "Rules for Design of Alloy 617 Nuclear Components to Very High Temperatures", Fatigue, Fracture and Risk, PVP-Vol. 215, ASME, 1991, pp. 147-153.

2. Kim, W-G., S-N. Yin, G-G. Lee, Y-W. Kim and S-J. Kim, "Creep Oxidation Behavior and CreepStrength Prediction for Alloy 617”, International Journal of Pressure Vessel and Piping, 87 (2010), pp. 289-295.

3. Schneider, K., W. Hartnagel, et al. "Creep Behavior of Materials for High-Temperature Reactor Application", Nuclear Technology 66 (1984), p. 289.

4. Viswanathan, R., J. F. Henry, et al., "US Program on Materials Technology for Ultra-supercritical Coal Power Plants", Journal of Materials Engineering and Perfromance, 14(3) (2005), pp. 281-292.

5. Penkalla, H.-J., H. Nickel and F. Schubert, "Multiaxial Creep of Tubes From Incoloy $800 \mathrm{H}$ and Inconel 617 Understatic and Cyclic Loading Conditions", Nuclear Engineering and Design, 112 (1989), pp. 279-289.

6. Lagneborg, R. "Bypassing of Dislocations Past Particles by a Climb Mechanism," Scripta Metallurgica, 7 (1973), pp. 605-614. 
7. Shewfelt, R. S. W. and L. M. Brown, "High-temperature Strength of Dispersion-hardened Single Crystals II. Theory", Philosophical Magazine, 35(4) (1977), pp. 945-962.

8. Evans, H. E. and G. Knowles, "Threshold Stress for Creep in Dispersion-Strengthened Alloys", Metal Science, 14(7) (1980), pp. 262-266.

9. Weertman, J., "An Experimental Relation Defining the Stress Dependence of Minimun Creep Rate in Metals", Transactions of the Metallurgical Society AIME, 227 (1963) pp. 1475-1476.

10. Sherby, O. D. and P. M. Burke, "Mechanical Behavior of Crystalline Solids at Elevated Temperature", Progress in Materials Science, 13(0) (1968), pp.323-390.

11. Mukherjee, A. K., J. E. Bird, et al., "Experimental Correlations for High-Temperature Creep", ASM Transactions Quarterly, 62(1) (1969), pp. 155-179.

12. Weertman, J. and P. Shahinian, "Creep of Polycrystalline Nickel", Journal of Metals, 8(10) (1956), pp. 1223-1226.

13. Brown, A. M. and M. F. Ashby "On the Power-law Creep Equation", Scripta Metallurgica, 14(12) (1980), pp. 1297-1302.

14. Johnson, W. R., C. R. Barrett, et al., "High-temperature Creep Behavior of Nickel-rich Ni-W Solid Solutions", 3(4) (1972), pp. 963-969.

15. Dorn, J. E. "Some Fundamental Experiments on High Temperature Creep", Journal of the Mechanics and Physics of Solids, 3(2) (1955), pp. 85-116.

16. Sherby, O. D., "Factors Affecting the High Temperature Strength of Polcyrystalline Solids", Acta Metallurgica, 10(2) (1962), pp. 135-147.

17. Zener, C. and J. H. Hollomon, "Effect of Strain Rate Upon Plastic Flow of Steel", Journal of Applied Physics, 15(1) (1954), pp. 22-32.

18. Wu, Q., H. Song, et al., "Microstructure of Long-term Aged IN617 Ni-base Superalloy", Metallurgical and Materials Transactions A: Physical Metallurgy and Materials Science, 39(11) (2008), pp. 2569-2585.

19. Singh, A. K., N. Louat, et al., "Dislocation Network Formation and Coherency Loss Around Gamma-Prime Precipitates in a Nickel Base Superalloy", Metallurgical Transactions A-Physical Metallurgy and Materials Science, 19(12) (1988), pp. 2965-2973.

20. Probst-Hein, M., A. Dlouhy, et al.,"Interface Dislocations in Superalloy Single Crystals", Acta Materialia, 47(8) (1999), pp. 2497-2510. 
21. Davies, P. W., G. Nelmes, et al., "Stress-Change Experiments During High-Temperature Creep of Copper, Iron, and Zinc", Metal Science, 7(1) (1973), pp. 87-92.

22. Parker, J. D. and B. Wilshire, "The Effect of a Dispersion of Cobalt Particles on High-Temperature Creep of Copper", Metal Science 9(1) (1975), pp. 248-252.

23. Artz, E. and D. S. Wilkinson, "Threshold Stresses for Dislocation Climb Over Hard Particles: The Effect of an Attractive Interaction", Acta Metall. 34(10) (1986), pp. 1893-1898.

24. McLean, M., "On the Threshold Stress for Dislocation Creep in Particle Strengthened Alloys", Acta Metall. 33(4) (1985), pp. 545-556.

25. Han, Y. and M. C. Chaturvedi, "A Study of Back Stress During Creep Deformation of a Superalloy Inconel 718", Materials Science and Engineering 85 (1987), pp. 59-65.

26. Marquis, E., D. Seidman, et al., "Precipitation Strengthening at Ambient and Elevated Temperatures of Heat-treatable Al(Sc) Alloys", Acta Materialia, 51 (2003), pp. 285-287.

27. Lagneborg, R. and B. Bergman, "The Stress/creep Rate Behaviour of Precipitation-hardened Alloys", Metal Science, 10 (1976), pp. 20-28.

28. Henderson, P. J. and M. McLean, "Microstructural Contributions to Friction Stress and Recovery Kinetics During Creep of the Nickel-base Superalloy IN738LC", Acta Metallurgica 31(8) (1983), pp. 1203-1219.

29. Evans, W. J. and G. F. Harrison, "Anelastic Deformation and Stress Reduction Experiments During Creep", Scripta Metallurgica, 9(3) (1975), pp. 239-246.

30. Hoffman, R. E., F. W. Pikus, et al., "Self-Diffusion in Nickel", Transactions of the American Institute of Mining and Metallurgical Engineers, 206(5) (1956), pp. 483-486.

31. Swalin, R. A., A. Martin, et al, "Diffusion of Mo in Ni", Transactions AIME, 207 (1957), p. 936.

32. Mankins, W L. and J. C. Hosier, "Microstructure and Phase Stability of Inconel 617”, Metallurgical Transactions, 5 (1973), pp. 2579-2590.

33. Fährmann, M., P. Fratz, et al., "Influence of Coherency Stress on Microstructural Evolution in Model Nickel-Al-Mo Alloys", Acta Metallurgica et Materialia, 43(3) (1995), pp. 1007-1022.

34. Fährmann, M., W. Hermann, et al., "Determination of Matrix and Precipitate Elastic Constants in (Gamma-Gamma') Ni-base Model Alloys and Their Relevance to Rafting", Materials Science and Engineering A, 260(1-2) (1999), pp. 212-221.

35. Pollock, T. M. and R. D. Field, "Dislocations and High-temperature Plastic Deformation of Superalloy Single Crystals", Dislocations in Solids, F. R. N. Nabarro and M. S. Duesbery, 11 (2002), pp. 547-618. 
36. Brown, L. M. and R. K. Ham, "Dislocation-Particle Interactions”, Strengthening Methods in Crystals, London, U.K., Elsevier, (1971), pp. 9-70.

37. Kozar, R., A. Suzuki, et al., "Strengthening Mechanisms in Polycrstalline Multimodal Nickel-Base Superalloys", Metallurgical and Materials Transactions A, 40A (2009), pp. 1588-1603.

38. Ardell, A. J., "Precipitation Hardening", Metallurgical Transactions A, 16A (1985), pp. 2131-2165.

39. Rösler, J. and E. Arzt, "The Kinetics of Dislocation Climb Over Hard Particles-I. Climb Without Attractive Particle-dislocation Interaction", Acta Metallurgica, 36(4) (1988), pp. 1043-1051.

40. Krug, M. E. and D. C. Dunand, "Modling the Creep Threshold Stress Due to Climb of a Dislocation in the Stress Field of a Misfitting Precipitate", Acta Materialia, 59 (2011), pp. 5125-5134.

41. Tung, Hsiao-Ming J. F. Stubbins, "Biaxial Thermal Creep of Inconel 617 Haynes 230”, poster presentation, NGNP Annual Review Meeting, Salt Lake City, UT, 2012.

42. Yao, H. T., F. Z. Xuan, Z. Wang, and S. T. Tu, “A Review of Creep Analysis and Design Under Multi-Axial Stress States” Nuclear Engineering and Design, 237 (2007), pp. 1969-1986.

43. Spindler, M. W., "The Multiaxial Creep Ductility of Austenitic Stainless Steel”, Fatigue and Fracture of Engineering Materials and Structures, 27, (2004), pp. 273-281.

44. Ali, H. O., and M. N. Tamin, "Modified Monkman-Grant Relationship for Austenitic Stainless Steel Foils", Journal of Nuclear Materials, 433 (2013), pp. 74-79. 